\title{
Simulation of the Air-Mass Transformation Process Using a Numerical Model with the Detailed Boundary Layer Parameterization
}

\author{
By Y. Yamagishi \\ Electronic Computation Center, Japan Meteorological Agency, Tokyo 100, Japan \\ (Manuscript received 11 March 1980, in revised form 17 June 1980)
}

\begin{abstract}
This paper describes the numerical simulation of the air-mass transformation by a three dimensional model. The model has a relatively high vertical resolution in the lower troposphere to improve the treatment of the vertical turbulent transfer processes in the boundary layer. The physical processes taken account of in the model are: (1) surface exchange of heat, moisture and momentum based on the similarity theory, (2) vertical turbulent transfer of heat, moisture and momentum based on the turbulent closure model of level 2 (Mellor and Yamada, 1974), (3) the parameterization of convection (the moist convective adjustment) and the condensation of moisture, (4) orographic effect, and (5) sub-grid scale lateral diffusion.

The model is applied to the observed meteorological situation under the northwest monsoon over the Sea of Japan. The simulated heat, moisture and momentum budget due to the sub-grid scale processes are discussed. The results are encouraging. However further improvement is required. In particular, the moist convective adjustment causes unrealistically large cooling and too humid stratification near the surface.

Preliminary result of a sensitivity test which is relevant to future improvement and remaining problems are also discussed.
\end{abstract}

\section{Introduction}

Operational numerical weather prediction models at JMA have the horizontal grid length of a hundred to several hundreds $\mathrm{km}$ and several layers in the vertical. These models fairly well simulate behaviors of synoptic scale disturbances and those of accompanying large scale moisture and precipitation field (e.g., Nitta et al., 1979). Actual weather phenomena are, however, much more complicated and subject to considerable variations in time and space. These variations are mostly due to the combination of various kinds of atmospheric motions and to modification caused mainly by earth's surface conditions such as orography and land-sea contrast. The Japanese Islands are highly mountainous and surrounded by the sea. Therefore, we should properly incorporate these surface conditions into the numerical model to improve numerical weather prediction prognoses around Japan.

We must increase the horizontal and vertical resolution of the model to simulate small scale features of the atmospheric motions. At the same time, it is also important to improve parameterization schemes used in the model. In order to see the effect of improving the treatment of the vertical turbulent transfer on the prediction, a model with a relatively high vertical resolution in the lower troposphere is constructed.

Using real data under the northwest winter monsoon, several experimental runs have been carried out with the model. The prognoses show that a large amount of heat and moisture supplied to the atmosphere from sea surface causes active air-mass transformation. Therefore the cases proved to be typical situations to assess the effect of the planetary boundary layer (PBL) parameterization.

Several authors have made numerical simulation of air-mass transformation in winter around Japan. For example, Asai and Nakamura (1978), using a two dimensional model, studied development process of a convectively mixed layer over 
warm sea during winter. Their model well simulates air-mass transformation in winter. However, their model is different from ours in that the former explicitly integrates evolution of smallscale convection which vertically transports heat, water vapor and momentum. Chouinard (1979), using a three dimensional model, discussed the effect of energy supply from sea surface on evolution of flow field around Japan during winter season. His model has fine vertical resolution (15 levels in the vertical) and adopts a detailed PBL parameterization. He, however, discusses little how his PBL parameterization simulates heat, moisture and momentum budget in the lower troposphere. This paper mainly discusses the degree of similarity of the heat, moisture and momentum transfer by the sub-grid scale processes to the observation. Overall assessment of the model performance must be made after the model is applied to various situations.

\section{Model and the computational procedure}

(1) Governing equations

The premitive equations based on the $\sigma$-system are used as follows:

Equation of motion

$$
\begin{gathered}
\frac{\partial}{\partial t}\left(\frac{\pi}{m^{2}} u\right)=-\frac{\partial}{\partial x}\left(\frac{\pi u u}{m}\right)-\frac{\partial}{\partial y}\left(\frac{\pi v u}{m}\right) \\
-\frac{\partial}{\partial \sigma}\left(\frac{\pi \dot{\sigma}}{m^{2}} u\right)+\frac{\pi}{m^{2}} v\left\{f-v \frac{\partial m}{\partial x}+u \frac{\partial m}{\partial y}\right\} \\
-\frac{\pi}{m} \frac{\partial \dot{\phi}}{\partial x}-C_{p} \frac{\pi \theta}{m} \frac{\partial P^{k}}{\partial x}+\frac{\pi}{m^{2}} F_{u}-\frac{g}{m^{2}}\left(\frac{g \vec{\tau}}{\partial \sigma}\right)_{x} \\
\frac{\partial}{\partial t}\left(\frac{\pi}{m^{2}} v\right)=-\frac{\partial}{\partial x}\left(\frac{\pi v u}{m}\right)-\frac{\partial}{\partial y}\left(\frac{\pi v v}{m}\right) \\
-\frac{\partial}{\partial \sigma}\left(\frac{\pi \dot{\sigma} v}{m^{2}}\right)-\frac{\pi}{m^{2}} u\left\{f-v \frac{\partial m}{\partial x}+u \frac{\partial m}{\partial y}\right\} \\
-\frac{\pi}{m} \frac{\partial \phi}{\partial y}-C_{p} \frac{\pi \theta}{m} \frac{\partial P^{k}}{\partial y}+\frac{\pi}{m^{2}} F_{v}-\frac{g}{m^{2}}\left(\frac{\partial \vec{\tau}}{\partial \sigma}\right)_{v}
\end{gathered}
$$

Thermodynamic equation

$$
\begin{aligned}
& \frac{\partial}{\partial t}\left(\frac{\pi}{m^{2}} \theta\right)=-\frac{\partial}{\partial x}\left(\frac{\pi u \theta}{m}\right)-\frac{\partial}{\partial y}\left(\frac{\pi v \theta}{m}\right) \\
& -\frac{\partial}{\partial \sigma}\left(\frac{\pi \dot{\sigma} \theta}{m^{2}}\right)+\frac{\pi}{m^{2}} F_{\theta}+\frac{\pi}{m^{2}} Q+\frac{g}{C_{p}} \frac{1}{m^{2}} \frac{\partial H}{\partial \sigma}
\end{aligned}
$$

Conservation of moisture

$$
\begin{gathered}
\frac{\partial}{\partial t}\left(\frac{\pi}{m^{2}} q\right)=-\frac{\partial}{\partial x}\left(\frac{\pi u q}{m}\right)-\frac{\partial}{\partial y}\left(\frac{\pi v q}{m}\right) \\
-\frac{\partial}{\partial \sigma}\left(\frac{\pi \dot{\sigma} q}{m^{2}}\right)+\frac{\pi}{m^{2}} F_{q}+\frac{\pi}{m^{2}} M+\frac{g}{m^{2}} \frac{\partial E}{\partial \sigma}
\end{gathered}
$$

Continuity equation

$$
\begin{aligned}
\frac{\partial}{\partial t}\left(\frac{\pi}{m^{2}}\right)= & -\frac{\partial}{\partial x}\left(\frac{\pi}{m} u\right) \\
& -\frac{\partial}{\partial y}\left(\frac{\pi}{m} v\right)-\frac{\partial}{\partial \sigma}\left(\frac{\pi}{m^{2}} \dot{\sigma}\right)
\end{aligned}
$$

Tendency equation

$$
\frac{\partial}{\partial t}\left(\frac{\pi}{m^{2}}\right)=-\int_{0}^{1}\left\{\frac{\partial}{\partial x}\left(\frac{\pi}{m} u\right)+\frac{\partial}{\partial y}\left(\frac{\pi}{m} v\right)\right\} d \sigma
$$

\section{Hydrostatic equation}

$$
\frac{\partial \phi}{\partial \sigma}=-C_{p} \theta \frac{\partial P^{k}}{\partial \sigma}
$$

Gas law

$$
\alpha=R T /\left(\pi \sigma+p_{t}\right)
$$

In the above equations, $\pi=p_{s}-p_{t}, p_{s}$ is the surface pressure, $p_{t}$ the pressure at the top of the model atmosphere, $m$ the map factor, $P=$ $p / 1000$ and $k=R / C_{p}$. The symbols $F_{u}, F_{v}, F_{\theta}$ and $F_{q}$ indicate the sub-grid scale horizontal diffusion terms for momentum ( $u$ and $v$ components), potential temperature and moisture, respectively. The horizontal stress vector due to the vertical turbulent fluxes of horizontal momentum is expressed as

$$
\vec{\tau}=-\frac{\rho^{2} g}{\pi} K_{m} \frac{\partial \vec{V}}{\partial \sigma},
$$

where $K_{m}$ is the eddy exchange coefficient for momentum and $\rho$ the air density. The vertical turbulent flux of heat and moisture is expressed as

$$
\begin{aligned}
& H=\left(C_{p} \rho^{2} g / \pi\right) K_{h} \frac{\partial \theta}{\partial \sigma}, \\
& E=\left(\rho^{2} g / \pi\right) K_{h} \frac{\partial q}{\partial \sigma},
\end{aligned}
$$

respectively, where $K_{h}$ is the eddy exchange coefficient being assumed to be common to both heat and moisture. The term $Q$ and $M$ indicate the non-adiabatic heating per unit mass and the moisture source per unit mass, respectively. These effects are caused by the parameterized convection and moisture condensation processes. Other notations are conventional. 


\section{(2) Structure of the model}

The model has thirteen levels in the vertical (Fig. 1). Vertical resolution is set relatively high in the lower troposphere to yield higher accuracy of the treatment of vertical turbulent transfer processes. All the meteorological variables are located on the same level. The eddy exchange coefficients are evaluated between the levels carrying meteorological variables. In horizontal, all the variables are defined on the same grid point. Upper and lower boundary conditions are $\dot{\sigma}=0$ at $\sigma=0(p=100 \mathrm{mb})$ and $\sigma=1\left(p=p_{s}\right)$, respectively. The boundary condition for calculating turbulent transfer effect will be explained later.

\section{(3) 'Forecast domain}

The forecast area covers mostly the Japanese Islands with a $35 \times 35$ horizontal grid net. The grid length is $63.5 \mathrm{~km}$ at $60^{\circ} \mathrm{N}$ on the stereographic projection map. This horizontal grid length is not fine enough to fully resolve small scale features of the motion, but it is chosen because of the limit of computer capability. For our present purpose, however, the above resolution will be sufficient. The highest altitude of the

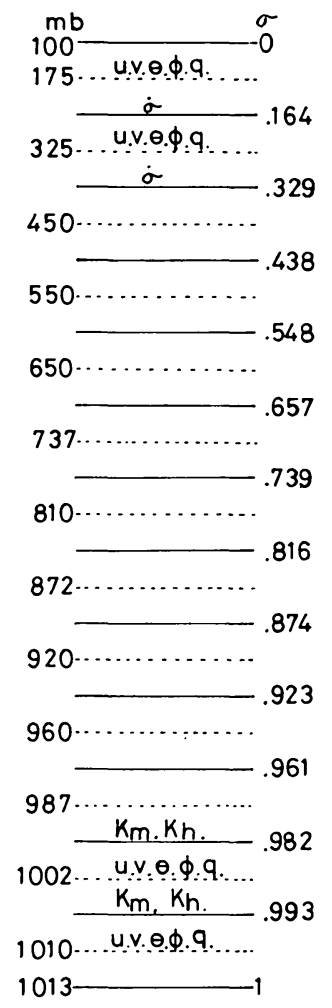

Fig. 1 Vertical structure of the model.

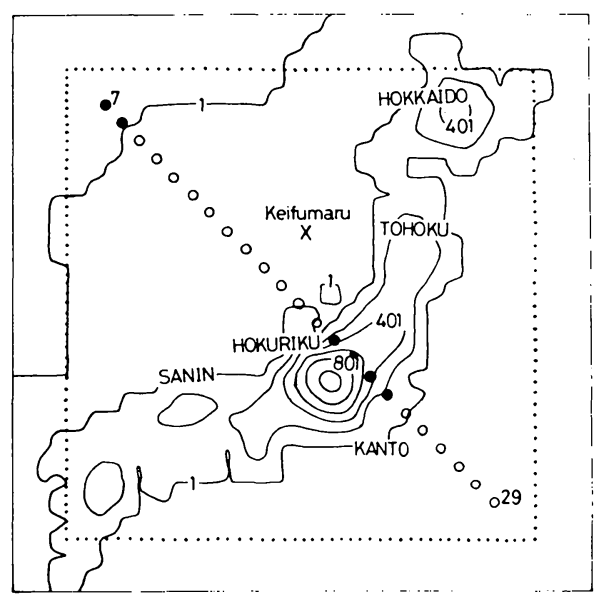

Fig. 2 Forecast domain. The solid line indicates the height contour of the orography above the sea level (meter), cross the position of the meteorological observation ship Kaifumaru and circles the grid points used to construct cross section of predicted field (see text). Black circles refer to land and open circles to sea. Numeral besides the circle signifies the grid number counted from the upper left corner to the lower right corner. Davies' boundary condition (see text) is applied outside of the dotted line.

orography in the model is about $1000 \mathrm{~m}$ and found around the central part of the Japanese Islands (Fig. 2). The height of the orography over the continental area which is located near the lateral boundary is set to be $1 \mathrm{~m}$ to avoid the computational difficulty associated with the lateral boundary.

(4) Physical processes

(a) Surface fluxes

The chosen parameterization scheme for the surface fluxes is based on Monin-Obukhov similarity theory. The profiles of wind, temperature and moisture depend on external parameters and on surface fluxes of momentum, heat and water vapor as

$$
\begin{aligned}
& \frac{k_{0} z}{u_{*}} \frac{\partial|\vec{V}|}{\partial z}=\phi_{m}\left(\frac{\vec{V}}{L}\right) \\
& \frac{k_{0} z}{\theta_{*}} \frac{\partial \theta}{\partial z}=\phi_{h}\left(\frac{z}{L}\right) \\
& \frac{k_{0} z}{q_{*}} \frac{\partial q}{\partial z}=\phi_{q}\left(\frac{z}{L}\right)
\end{aligned}
$$

where $k_{0}$ is the Karman's constant and $L=$ 
$0 u_{*}^{2} / k_{0} g \theta_{*}$ is the Monin-Obukhov length*. The quantities $u_{*}, \theta_{*}$ and $q_{*}$ are defined in terms of the surface fluxes of momentum, heat and water vapor as

$$
\begin{aligned}
& \tau_{0}=\rho_{0}\left|\overrightarrow{w^{\prime}} \overrightarrow{\vec{V}^{\prime}}\right|_{0}=\rho_{0} u_{*}^{2} \\
& H_{0}=\rho_{0} C_{p}\left(\overline{w^{\prime} \theta^{\prime}}\right)_{0}=-\rho_{0} C_{p} u_{*} \theta_{*} \\
& E_{0}=\rho_{0}\left(w^{\prime} q^{\prime}\right)_{0}=-\rho_{0} u_{*} q_{*}
\end{aligned}
$$

where suffix 0 indicates the value at the earth's surface. We adopt the formulae for $\phi_{m}, \phi_{h}, \phi_{q}$ derived by Businger et al. (1971):

$$
\begin{aligned}
\phi_{m} & =\left(1-15 \frac{z}{L}\right)^{-1 / 4} & & \frac{z}{L} \leqq 0 \\
& =\left(1+4.7 \frac{z}{L}\right) & & \frac{z}{L}>0 \\
\phi_{h} & =0.74\left(1-9 \frac{z}{L}\right)^{-1 / 2} & & \frac{z}{L} \leqq 0 \\
& =0.74+4.7 \frac{z}{L} & & \frac{z}{L}>0
\end{aligned}
$$$$
\phi_{q}=\phi_{h}
$$

The integrated version of (9) are given by (Paulson, 1970)

$$
\begin{aligned}
& |V(z)|=\frac{u_{*}}{k_{0}}\left(\ln \left(\frac{z}{z_{0}}\right)-\phi_{1}\left(\frac{z}{L}\right)\right) \\
& \Delta \theta \equiv \theta(z)-\theta\left(z_{0}\right)=0.74 \frac{\theta_{*}}{k_{0}}\left(\ln \left(\frac{z}{z_{0}}\right)-\phi_{2}\left(\frac{z}{L}\right)\right) \\
& \Delta q \equiv q(z)-q\left(z_{0}\right)=0.74 \frac{q_{*}}{k_{0}}\left(\ln \left(\frac{z}{z_{0}}\right)-\phi_{2}\left(\frac{z}{L}\right)\right)
\end{aligned}
$$

with

$$
\begin{aligned}
\phi_{1}= & \ln \left(\frac{1+\phi_{m}^{-1}}{2}\right)^{2}\left(\frac{1+\phi_{m}^{-2}}{2}\right) & & \\
& -2 \tan ^{-1} \phi_{m}{ }^{-1}+\frac{\pi}{2} & & \frac{z}{L} \leqq 0 \\
= & -4.7 \frac{z}{L} & & \frac{z}{L}>0 \\
\phi_{2}= & \ln \left(\frac{1+\phi_{h}^{-1}}{2}\right)^{2} & & \frac{z}{L} \leqq 0 \\
= & -6.35 \frac{z}{L} & & \frac{z}{L}>0
\end{aligned}
$$

where $z_{0}$ is the roughness parameter. We take

\footnotetext{
* We neglect the role of water vapor in altering air density to calculate surface flux and vertical turbulent transfer above the surface layer. The error will not be large in the present study because of small amount of water vapor contained in the atmosphere,
}

the height of the lowest model level as the height $z$ in (12). We assume that the values at $z_{0}$ are the same as those at the surface. The relation (12) calculates the eddy fluxes $u_{*}^{2}, u_{*} \theta_{*}, u_{*} q_{*}$ given the model variables $\vec{V}(z), \Delta \theta$ and $\Delta q$. In unstable conditions, it is not possible to solve (12) analytically. To save the computation time we use the following approximation (Barker et al., 1975) to relate $z / L$ explicitly with the bulk Richardson number, $R_{i B}$.

$$
\begin{aligned}
& \frac{z}{L}=R_{i B} \cdot f\left(C_{N}\right) \\
& f\left(C_{N}\right)=0.471 \cdot C_{N}-1.045 \quad\left(\frac{z}{L} \leqq-0.05\right) \\
& C_{N} \equiv \frac{1}{k_{0}} \ln \left(\frac{z}{z_{0}}\right) \\
& R_{i B} \equiv-\frac{g z \Delta \theta}{\theta}|\vec{V}|^{2}
\end{aligned}
$$

We use the analytical expression for stable case when $z / L>-0.05$.

The sea surface temperature is kept constant throughout the time integration. Over the sea, the following relation (Clarke, 1970) closes the flux calculation

$$
z_{0}=0.032 u_{*}{ }^{2} / g \quad\left(z_{0} \geqq 0.0015 \mathrm{~cm}\right)
$$

The heat balance equation at the surface determines the ground surface temperature over the land

$$
\begin{aligned}
& R_{s}(1-A)+F+\rho_{0} C_{p} u_{*} \theta_{*}+<\rho_{0} u_{*} q_{*} \\
& \quad-\left(H_{g}\right)_{0}-\varepsilon \sigma\left(T_{g}\right)^{4}=0
\end{aligned}
$$

where $R_{s}$ is the solar radiation reaching the ground, $A$ the albedo of the surface, $F$ the downward long wave radiation absorved at the surface, $T_{g}$ the ground temperature, $\sigma$ the Stefan-Boltzman constant, $\varepsilon$ the emissivity of the ground surface in the infrared, $\Lambda$ the latent heat of water vapor and $H_{g}$ the heat conduction into the soil. The term $R_{s}$ depends on the local time at each grid point. Thus

$$
R_{s}=(\mathrm{tau})\left(R_{s}\right)_{\infty} \cos \zeta
$$

where $\zeta$ is the Zenith angle, $\left(R_{s}\right)_{\infty}$ the solar constant, (tau) the transmissivity of the atmosphere. Empirical formula after Kondo (1976) is used for (tau). Brunt's formula calculates the downward long wave radiation. Temperature in the soil is not predicted but kept constant at an appropriate depth to calculate $H_{g}$. We apply Newton-Raphson iteration method to determine $\mathrm{T}_{\mathrm{g}}$ from (15) assuming that $\phi_{1}$ and $\phi_{2}$ are con- 
stant during iteration process. After $T_{g}$ has been obtained we check the absolute change in $\theta_{*}$. If the absolute change in $\theta_{*}$ is greater than a critical value we recalculate $\phi_{1}$ and $\phi_{2}$ with the new value of $T_{g}$ and repeat the iteration. Table $\mathrm{A} \cdot 1$ gives various quantities used in (15) (Appendix).

The fluxes thus determined are the lower boundary conditions for calculating the vertical turbulent transfer;

$$
\begin{aligned}
& H_{0}=\left(\left(C_{p} \rho^{2} g / \pi\right) K_{h} \frac{\partial \theta}{\partial \sigma}\right)_{0}, \\
& E_{0}=\left(\left(\rho^{2} g / \pi\right) K_{h} \frac{\partial q}{\partial \sigma}\right)_{0}, \\
& \overrightarrow{\tau_{0}}=\left(-\left(\rho^{2} g / \pi\right) K_{m} \frac{\partial \vec{V}}{\partial \sigma}\right)_{0} .
\end{aligned}
$$

(b) Turbulent fluxes of heat, moisture and momentum above the surface layer

Miyakoda and Sirutis (1977) classify the parameterization of the dry sub-grid scale processes in the PBL into three types, i.e., turbulent closure model, mixed layer theory and the method which tries to extend the similarity theory to the whole PBL. In the present experiment we use the turbulent closure model of level 2 (Mellor and Yamada, 1974). The vertical heat transfer by dry sub-grid scale processes is all parameterized by the closure model and dry convective adjustment is not used at all. Recently Yamada and Mellor (1979) coupled the closure model (level 2.5) with the cloud model to simulate BOMEX data. In their model any other parameterization of moist convection is not included. In the present experiment we apply the closure model combining with the moist convective adjustment as Miyakoda and Sirutis (1977) did. The closure model can be applied not only to the PBL, but above the PBL as well. The exchange coefficient can be determined from the local wind shear and the local stability. Therefore the scheme is very convenient for applying to the multi-layer numerical model.

The vertical turbulent fluxes of the momentum and heat are expressed as follows:

$$
\begin{aligned}
& \left(\frac{\vec{\tau}}{\rho}\right)_{x}=-\overline{u^{\prime} w^{\prime}}=K_{m} \frac{\partial u}{\partial z} \\
& \left(\frac{\vec{\tau}}{\rho}\right)_{y}=-\overline{v^{\prime} w^{\prime}}=K_{m} \frac{\partial v}{\partial z} \\
& \frac{H}{\rho C_{p}}=\bar{\theta}^{\prime} w^{\prime}=-K_{h} \frac{\partial \theta}{\partial z} \\
& \frac{E}{\rho}=\overline{q^{\prime}} \overline{w^{\prime}}=-K_{h} \frac{\partial q}{\partial z}
\end{aligned}
$$

$$
\begin{aligned}
& K_{m}=l^{2}\left|\frac{\partial \vec{v}}{\partial z}\right| S_{m} \\
& K_{h}=l^{2}\left|\frac{\partial \vec{v}}{\partial z}\right| S_{h}
\end{aligned}
$$

The terms $S_{m}, S_{h}$ are calculated from flux Richardson number, $\boldsymbol{R}_{\boldsymbol{f}}$ :

$$
\begin{aligned}
& S_{m}=B_{1}{ }^{1 / 2}\left(1-R_{f}\right)^{1 / 2}\left(\tilde{S}_{m}\right)^{3 / 2}>0
\end{aligned}
$$

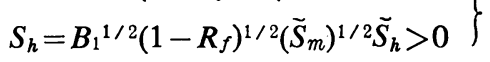

$$
\begin{aligned}
& R_{f}<R_{f c} \equiv 0.213 \\
& S_{m} \equiv S_{h} \equiv 0 \quad R_{f} \geqq R_{f c} \\
& \tilde{S}_{m}=3 A_{1} \frac{\gamma_{1}-c_{1}-\left(6 A_{1}+3 A_{2}\right) \delta / B_{1}}{\gamma_{1}-\gamma_{2} \delta}\left(\gamma_{1}-\gamma_{2} \delta\right) \\
& \tilde{S}_{h}=3 A_{2}\left(\gamma_{1}-\gamma_{2} \delta\right) \\
& \delta \equiv R_{f} /\left(1-R_{f}\right)
\end{aligned}
$$

where $\gamma_{1}, \gamma_{2}$ are constants and $R_{f}$ is the flux Richardson number. The length scale $l$ is given by

$$
l=\frac{k_{0} z}{1+k_{0} z / l_{0}}
$$

where

$$
\begin{aligned}
& l_{0}=0.10 \frac{\int_{0}^{\infty} b z d z}{\int_{0}^{\infty} b d z} \\
& b^{2}=\bar{u}^{\prime 2}+\bar{v}^{\prime 2}+\bar{w}^{\prime 2}
\end{aligned}
$$

The turbulent intensity $b^{2}$ is related to the destruction by transfer to the mean flow and generation by buoyancy as

$$
\frac{b^{3}}{15 l}=-\overline{u^{\prime}} \overline{w^{\prime}} \frac{\partial u}{\partial y}-\overline{v^{\prime}} \overline{w^{\prime}} \frac{\partial v}{\partial y}+\frac{g}{\theta} \overline{w^{\prime} \bar{\theta}^{\prime}}
$$

In the present experiment, we modify the above original scheme in the following two points. First we do not solve (17) through (20) iteratively to determine the vertical fluxes. Instead we use a following simple relation to save the computation time.

$$
l_{0}=\frac{B u_{*}}{f}, \quad B=\text { const. }
$$

We determine the magnitude of $B$ so that the formula (21) gives the similar result with the formulae (17) through (20) in the experiment using a one-dimensional dry model (see Appendix). In the second we assume that the terms $S_{m}, S_{h}$ have minimum non zero value even in very stable regime; the magnitude of $S_{m}, S_{h}$ are set to be equal to the value at $R_{f}=0.15$ when 
$R_{f}$ is greater than 0.15 . We discuss this assumption later in section 3 in connection with the moist convective adjustment.

We assume $(\partial / \partial z)\left(\bar{\alpha}^{\prime} \omega^{\prime}\right)=0(\alpha=u, v, \theta$ or $q)$ at the uppermost level. This assumption provide the upper boundary condition for calculating the vertical turbulent transfer.

(c) Parameterization of convection and condensation

When the relative humidity exceeds $100 \%$, we adjust the water vapor and temperature to make the relative humidity $100 \%$ irrespective of the vertical static stability. The excess moisture is instantaneously removed from the model atmosphere and may be regarded as the large scale condensation. Following the above procedure, when the temperature lapse rate exceeds the critical value $\Gamma_{c}$, the moist convective adjustment takes place to restore $\Gamma_{c}$, while keeping the relative humidity unchanged. The value of $\Gamma_{c}$ depends on the relative humidity. Excess moisture is removed from the model and considered the convective condensation. The above procedures are identical to those of the JMA operational numerical prediction model (Nitta et al., 1979).

(d) Sub-grid scale lateral diffusion

The Fickian-type lateral diffusion term is applied to the horizontal diffusion of momentum, temperature and water vapor, i.e.,

$$
F_{\alpha}=\nu \nabla^{2} \alpha, \quad \alpha=u, v, \theta \text { or } q
$$

The numerical value of the coefficient $\nu$ is determined on the basis of the theory of the twodimensional turbulence (Leith, 1969),

$$
\nu=\gamma|\nabla \zeta| d^{3}
$$

where $\zeta$ is the relative vorticity, $d$ the grid distance and $\gamma$ the non-dimensional constant. In the present experiment $\gamma$ is 1.25 .

(e) Radiative process in the atmosphere is not taken into account.

\section{(5) Computational procedures}

(a) Lateral boundary condition

We apply the procedure proposed by Davies (1976), which may suppress the noise near the boundary. The tendency is modified near the boundary such as

$$
\frac{\partial \alpha}{\partial t}=\cdots \quad-K(\alpha-\check{\alpha})
$$

where $\alpha=u, v, \theta, q$ or $\pi$.

The symbol $\tilde{\alpha}$ is a specified value of $\alpha$ to which the predicted interior value of $\alpha$ should approach. The term $K$ is defined only at the outermost five grid points along the lateral boundary and the magnitude increases towards the boundary. Over the remaining grid points, $K$ is zero. In the present experiment, we specify the value of $\tilde{\alpha}$ by linearly interpolating the observed values at the initial time and those at 12 hours later. Ragged irregular patterns of the predicted field are obtained near the lateral boundary, particularly in the vertical motion field. However, this seems not to be critical for our present purposes as far as we confine the discussion inside the forecast domain.

\section{(b) Initialization procedure}

The balance equation and the quasi-geostrophic $\omega$-equation calculate the non-divergent and divergent component of the initial wind field, respectively. Both the equations are solved on the grid net of the mesh size of $63.5 \mathrm{~km}$ (the fine mesh net). We obtain the height field on the fine mesh net by bicubic interpolation of the objectively analyzed field on the grid net of the mesh size of $381 \mathrm{~km}$.

\section{(c) Time integration}

We combine the leap-frog method and the Euler-backward method to integrate all the terms except the vertical turbulent transfer one which is integrated implicitly to avoid the computational instability. The time interval $\Delta t$ is 80 seconds. The surface fluxes and the vertical turbulent fluxes are evaluated at every five time steps. The moist convective adjustment and the condensation of water vapor is taken place at every fifteen time steps.

\section{Discussion of the results}

This section discusses the results of 12-hour experimental predictions. Three cases are chosen. The initial data of the three cases are those at 00 GMT 31 January 1977 (Case 1), 00 GMT 2 February 1977 (Case 2) and 00 GMT 16 February 1977 (Case 3). The first case will be most intensively discussed. The first subsection briefly describes the observed field. The next subsection discusses vertical transport of heat, moisture and momentum due to the sub-grid scale processes. Subsection 3 will present predicted horizontal field and vertical distribution of sub-grid scale effect. Finally subsection 4 will discuss energy supply from sea surface and condensation amount.

\section{(1) Observed field}

Special upper air observation over the Sea of Japan made by the meteorological observation 
ship Keifumaru is available from 30 January to 8 February 1977.

In Fig. 3 shown are the vertical profile of the thermodynamic quantities and wind speed at 00 GMT 31 January and at 00 GMT 2 February. The observation position is shown with a cross in Fig. 2.* The case on 31 January shows the situation just in front of the major upper cold vortex which moved from west to east across Hokkaido. The situation on 2 February is typical of that just after the passage of cold vortex.

Temperature stratification is nearly neutral or slightly stable in the layer between the top of the surface layer and the bottom of the stable layer. The base of the stable layer is observed around $180 \mathrm{mb}$ above the surface. The relative humidity is maximum around the base of the stable layer. The specific humidity decreases gradually from the surface upward. The wind speed rapidly increases upward from the level slightly below the stable layer. The similar vertical profiles of thermodynamic quantities are found almost every day throughout the period. Fig. 4 shows mean vertical profile averaged over 19 observations during the above 10 days. The values at the same pressure difference relative to the base of the stable layer are averaged to construct the above mean profile. The characteristics mentioned above are clearly observed in the mean field. The

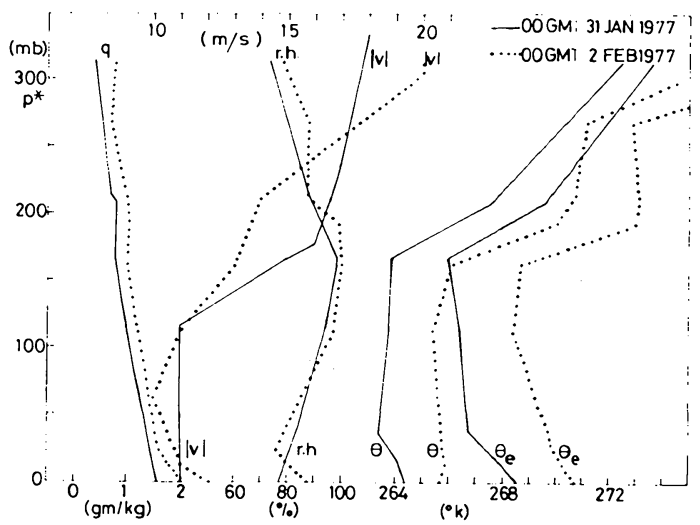

Fig. 3 Vertical profile of specific humidity $(q)$, wind speed $(|\mathrm{v}|)$, relative humidity $(r: h)$, potential temperature $(\theta)$ and equivalent potential temperature $\left(\theta_{e}\right)$ observed by Kaifumaru at 00 GMT 31 January and at 00 GMT 2 February. Height scale is expressed by $p^{*}\left(p^{*}=\right.$ $p_{\text {surface }}-p$ ) in this paper.

* The ship positions are not the same day by day. However they are located within about $70 \mathrm{~km}$ of the cross in Fig. 2.

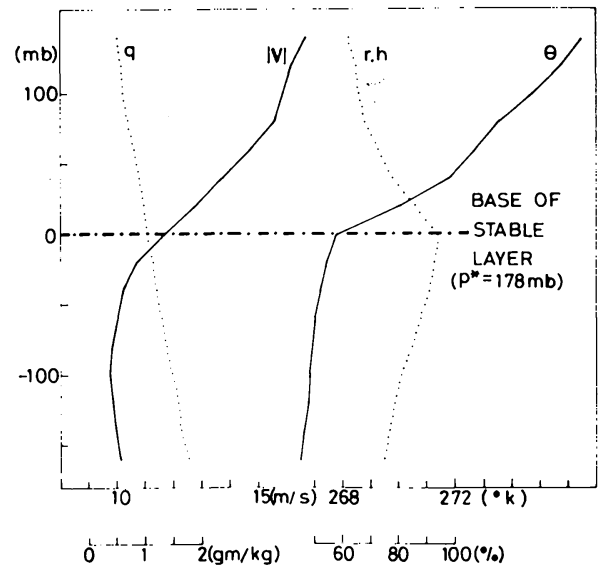

Fig. 4 Mean vertical profile of observed thermodynamic quantities and wind speed. Notations are the same with those of Fig. 3.

vertical profiles shown in Figs. 3 and 4 suggest a well mixed layer capped by the stable layer. The situation has close similarity with those observed around the AMTEX area under the cold air outbreak situation (e.g., Saito, 1975). On 16 February a major cold vortex at $500 \mathrm{mb}$ is observed around Hokuriku District. We have no upper air observation over the Sea of Japan in this case. However the convection near the cold vortex center will reach higher than the other two cases mentioned above (e.g., Matsumoto and Ninomiya, 1967).

\section{(2) Vertical transport of heat, moisture and momentum due to the sub-grid scale processes}

In order to see how our parameterization simulate the characteristics of the mixed layer, we investigate the results of three experiments, i.e., experiment by $\mathrm{D}$ model, $\mathrm{L}$ model and $\mathrm{M}$ model. The $\mathrm{D}$ model excludes both the large scale condensation and the moist convective adjustment. The $\mathrm{L}$ model excludes the moist convective adjustment. The $\mathbf{M}$ model includes both the large scale condensation and the moist convective adjustment.

When the convective adjustment is taken place the temperature lapse rate, $\Gamma$ becomes $\Gamma_{m} \leqq \Gamma$ $\leqq \Gamma_{d}$, where $\Gamma_{m}$ and $\Gamma_{d}$ are moist adiabatic and dry adiabatic lapse rate, respectively. The flux Richardson number usually exceeds the critical value under the above temperature lapse rate. Consequently the vertical turbulent transfer effect is found to work within the very shallow 
layer above the surface. In order to avoid this difficulty, we assume as mentioned in section 2 that the terms $S_{m}, S_{h}$ in (17) be equal to the value at $R_{f}=0.15$ when $R_{f}$ is greater than 0.15 . This assumption is employed throughout the present experiment. Appendix 3 will discuss the effect of this assumption on the vertical temperature distribution.

Fig. 5 shows potential temperature, relative humidity predicted at $t=12$ and total warming (cooling) rate, total moistening (drying) rate due to the vertical sub-grid scale processes for the Case 1. The effect of the sub-grid scale processes are averaged over 6 hours from $t=7$ to $t=12$. The thin solid line indicates the initial potential temperature profile. All the model variables refer to the grid point near the cross in Fig. 2. The potential temperature and the relative humidity field observed by Keifumaru are also inserted in the figure. In Fig. 5 through Fig. 10 all the predicted results refer to the same grid point. Fig. 6 shows the same with Fig. 5 for the Case 2 except that the result of the $\mathrm{D}$ model is not shown. The stable layer is not distinct in the observed field in the Case 1 but it may be located at about $200 \mathrm{mb}$ above the surface.

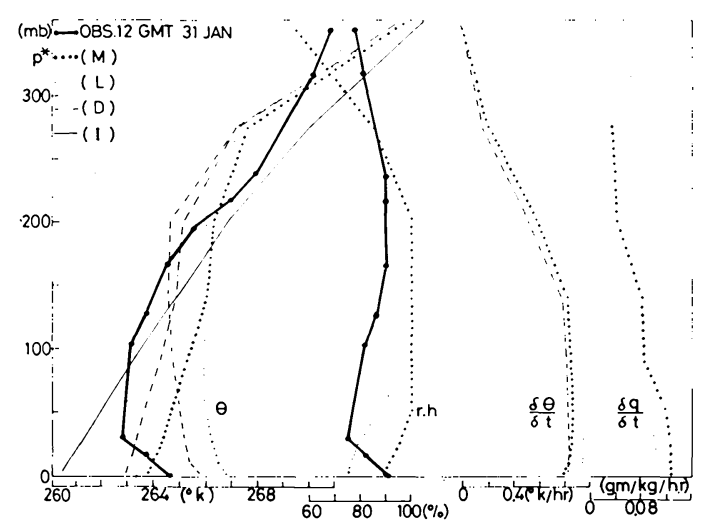

Fig. 5 The vertical distribution of predicted potential temperature $(\theta)$, relative humidity $(r . h)$, total warming rate $(\delta \theta / \delta t)$ and total moistening rate $(\delta q / \delta t)$ due to the vertical sub-grid scale processes for the Case 1. The symbols $\mathrm{M}, \mathrm{L}$ and $\mathrm{D}$ signify the $\mathrm{M}$ model, $\mathrm{L}$ model and the $\mathrm{D}$ model, respectively. The symbol I indicates the initial state of the model. The dash dotted line shows the potential temperature predicted by the $M$ model using reduced sea surface temperature (see section 4).

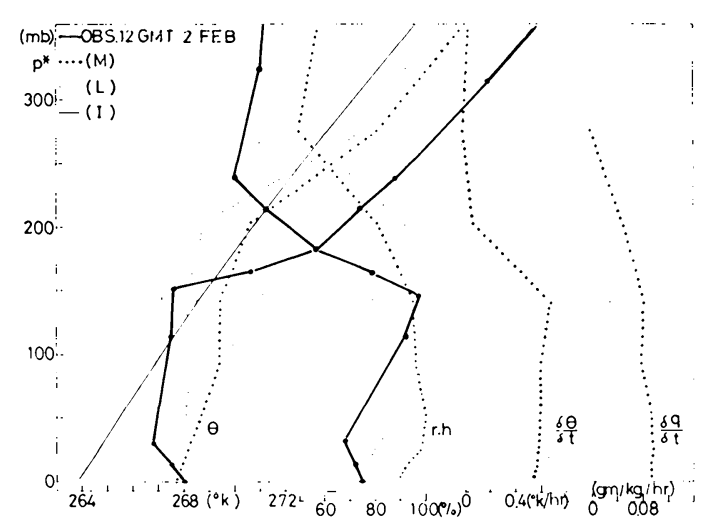

Fig. 6 The same with Fig. 5 but for the Case 2.

First we compare results of the $\mathrm{M}$ model with those of the $\mathrm{L}$ model. The following predicted features are common to both the Case 1 and the Case 2. The moist convective adjustment takes place from the lowest level in the $\mathrm{M}$ model. Therefore the temperature stratification is nearly moist adiabatic below the stable layer and is more stable than the observed one. The potential temperature decreases upward or almost uniform bclow the stable layer in the $\mathrm{L}$ model. The temperature stratification is less stable than the observed one in the $\mathrm{L}$ model. Both the models predict the bases of the stable layer at the same level. The bases of the predicted stable layers are higher than the observed ones by about 60 mbs. This discrepancy results from the following; the predicted temperature is higher than the observed one below the stable layer and is lower than the observed one above that level. The temperature changes due to the sub-grid scale processes are very small above the stable layer. Therefore the prediction error in that layer results from the large scale adiabatic motion. The sea surface temperature used in the present experiment is higher than that observed by Keifumaru by $\sim 5^{\circ} \mathrm{C}$ (in the Case 1 ) and $\sim 2^{\circ} \mathrm{C}$ (in the Case 2 ) at the grid point we are concerned now. This will partly explain the fact that predicted temperature is higher than the observed one below the observed stable layer. Reducing the sea surface temperature by $2^{\circ} \mathrm{C}$ decreases the predicted potential temperature in that layer about $1^{\circ} \mathrm{K}$ (dash dotted line in Fig. 5). The sensitivity of the model to the change of sea surface temperature will further be discussed in section 4 .

Both the models predict more humid stratification than the observed one. In particular the $M$ 
model produces very humid stratification near the surface. The $\mathrm{L}$ model simulates the vertical distribution of the relative humidity better than the $M$ model.

In the second place we compare results of the D model with those of the other two models. Asai and Nakamura (1978) indicate that the convective cloud play an effective role in deepening a convectively mixed layer. In the present experiment the latent heat released by condensation warms the airmass below the stable layer. Therefore the $\mathrm{L}$ model and the $\mathrm{M}$ model produce higher temperature than the $\mathrm{D}$ model below the stable layer. This will shift the predicted stable layer upward. This effect is not remarkable but can be noticed in the potential temperature profile of Fig. 5.

Fig. 7(a), (b) show the components contributing to warming and moistening of the airmass, respectively, for the Case 1. The values are
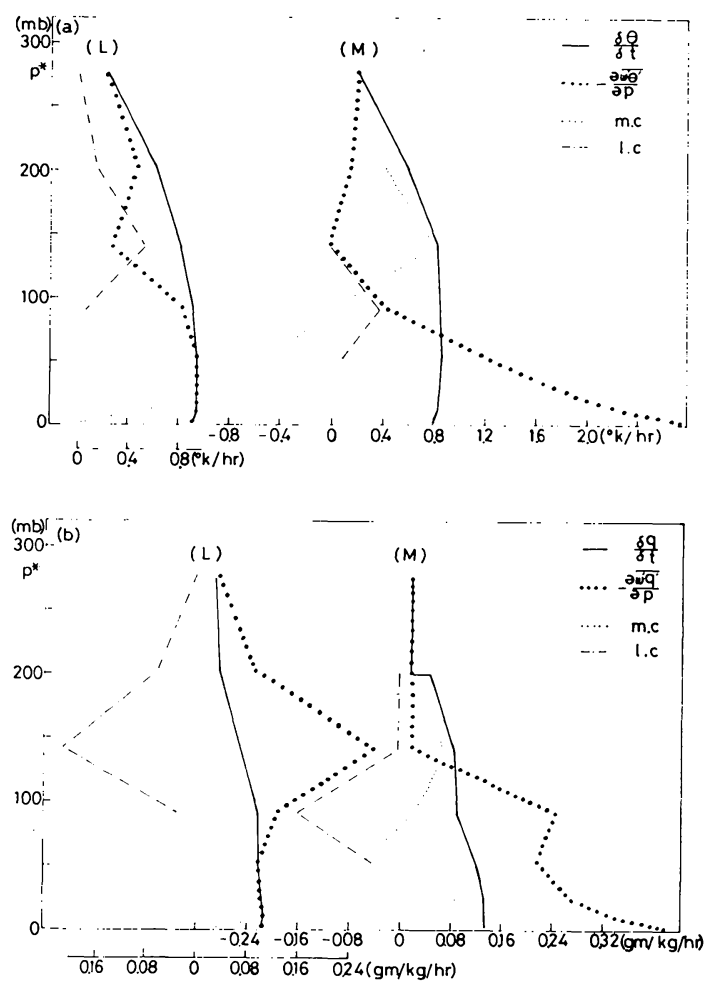

Fig. 7(a) Heating rate due to the convergence of the vertical turbulent transfer $\left(-\partial / \partial p\left(\overline{\left.\omega^{\prime} \theta^{\prime}\right)}\right)\right.$, moist convective adjustment (m.c), large scale condensation (1.c) and the sum of them $(\delta \theta / \delta t)$ for the Case 1. (b) Moistening rate for the Case 1 . Notations are similar to those of (a). averaged over 6 hours from $t=7$ to $t=12$. The vertical distribution of the each component differs greatly for the $\mathrm{L}$ model and for the $\mathrm{M}$ model: the heating and decreasing of water vapor due to the large scale condensation is maximum at $p^{*} \approx$ $140 \mathrm{mb}$ in the $\mathrm{L}$ model, while it is maximum at $p^{*} \approx 90 \mathrm{mb}$ in the $\mathrm{M}$ model.* However the sums of the components differ little in the two models. The warming and the moistening rate due to the convergence of the vertical eddy transfer are unrealistically large near the surface in the $M$ model. These are computationally caused to compensate the cooling and decreasing of moisture by the moist convective adjustment scheme.

Next we will discuss the momentum budget for the Case 1. In Fig. 8 shown are the vertical profiles of the observed and the predicted wind speed. The predicted wind speed is more uniform than the observed one below $p^{*} \approx 150 \mathrm{mb}$. The $M$ model predicts about $1 \mathrm{~m} / \mathrm{s}$ weaker wind speed than the other two models near the surface. Figs. 9(a), (b) show the momentum budget in the $\mathrm{L}$ model and in the $\mathbf{M}$ model, respectively. The thick solid, thin solid and dotted lines indicate the momentum change due to the vertical turbulent transfer, the ageostrophic wind components and the sum of these two components, respectively. In Fig. 10 shown are the kinetic energy dissipation due to the vertical transfer and the angle between the predicted wind and the geostrophic wind. The angle is counted positive when wind blows toward lower pressure. The above results refer to the last one hour of the prediction period, that is, from $t=11$ to $t=12$.

The momentum change due to the vertical turbulent transfer nearly compensates that due

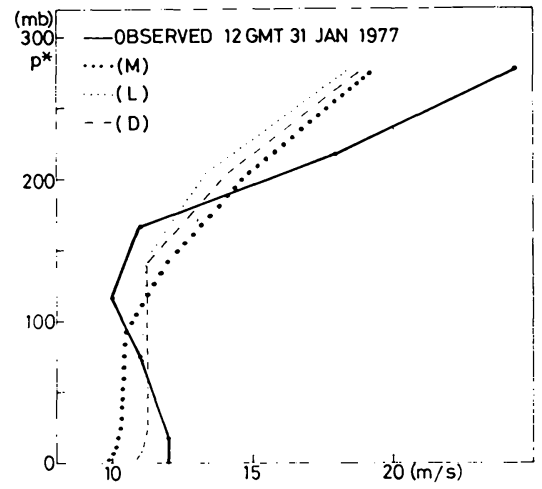

Fig. 8 Observed and the predicted vertical profile of the wind speed.

* We define $p^{*}$ as $p^{*}=p_{\text {surface }}-p$, where $p$ is the pressure. 

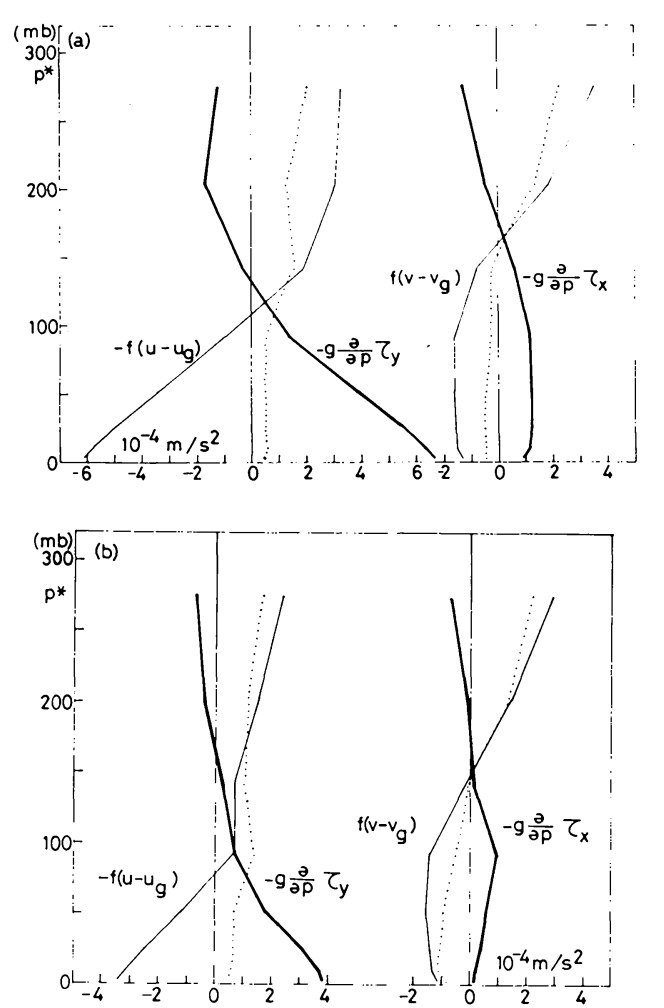

Fig. 9 The momentum budget in the $\mathrm{L}$ model (a) and in the M model (b).

to the ageostrophic wind component below $p^{*} \sim$ $120 \mathrm{mb}$ in the $\mathrm{L}$ model. The deviation of the calculated wind direction from the geostrophic wind changes sign at about $100 \mathrm{mb}$ above the surface in the L model, i.e., the flow toward the lower pressure below that level to the flow toward the higher pressure above it. The general features of the momentum budget predicted by the $M$ model are similar to those predicted by the $\mathrm{L}$ model. However we notice the following difference; the momentum change due to the turbulent transfer in the $\mathrm{M}$ model is weaker and the effect is confined in slightly lower layer than that in the $\mathrm{L}$ model. The magnitude of the kinetic energy dissipation by shearing stress and the cross isobaric angle of the wind near the surface are smaller in the $M$ model than in the $L$ model. The features of momentum budget predicted by the D model (not shown here) are almost the same with those predicted by the $\mathrm{L}$ model.

We have no analytical study of the momentum budget over the Sea of Japan to compare with the present experiment. Ninomiya (1976), Ninomiya and Akiyama (1976) studied using the budget method the heat energy and the kinetic
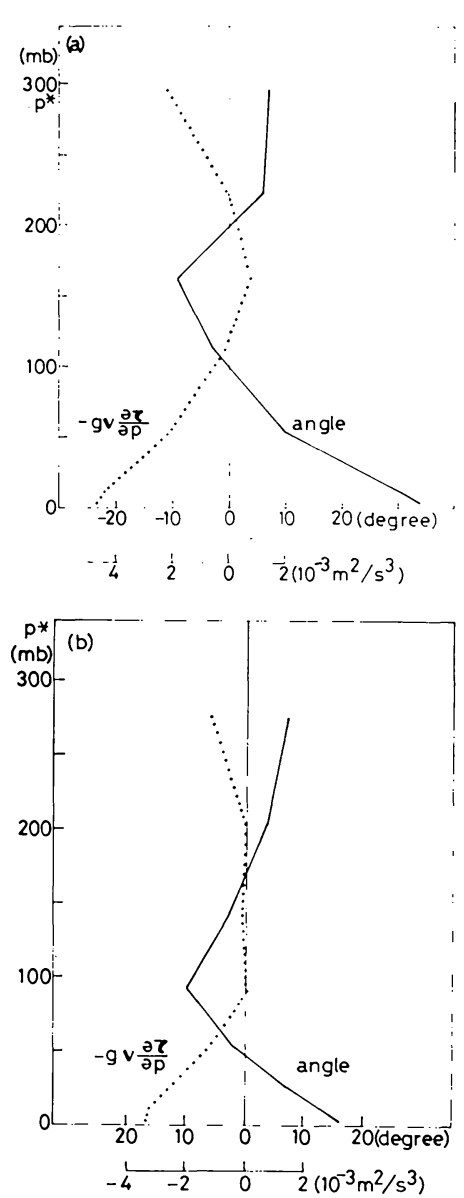

Fig. 10 The kinetic energy dissipation due to the shearing stress and the angle between the wind and the geostrophic wind for the $\mathrm{L}$ model (a) and for the $M$ model (b).

energy budget under the cold air outbreak around the AMTEX area. A well mixed layer capped by the stable layer is observed in the AMTEX area under the cold air outbreak. The order of magnitude of heat, momentum transfer and kinetic energy dissipation due to the sub-grid scale processes simulated in the present experiment roughly agree with those obtained by them. However the detailed comparison can not be made since the large scale flow situation of our case is not the same with that studied by the above mentioned authors.

We investigated in this subsection heat, moisture and momentum budget due to the sub-grid scale processes. We may say that the present experiment simulate general features of the mixed 
layer capped by the stable layer. We compared the results by the $M$ model with those by the $L$ and $\mathrm{D}$ models to see the effect of convection parameterization on simulation of the mixed layer. Our comparison is not conclusive as yet. Further extensive investigation is required to improve the convection parameterization. However, in the following we will discuss the results predicted by the $\mathrm{M}$ model.

\section{(3) Predicted surface field and the vertical distribution of the sub-grid scale effect}

Fig. 11 shows the surface pressure field (a) and the horizontal wind field at the lowermost level (b) at $t=12$ for the Case 1. In Fig. 12 shown

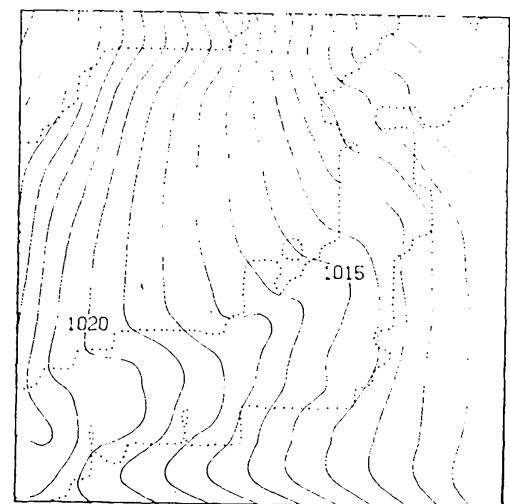

(a)

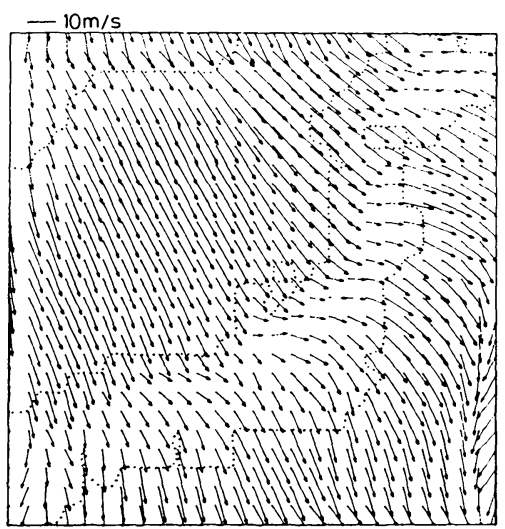

(b)

Fig. 11 Predicted sea surface pressure (a, contour interval $1 \mathrm{mb}$ ) and horizontal wind field at the lowermost level (b) at $t=12$. Only the area within the dotted line in Fig. 2 is shown. Wind scale is shown on the upper left corner. Periphery of the land is denoted by the dotted line. is the manually analyzed surface synoptic chart at 12 GMT 31 January 1977 . The model predicts the cyclonic curvature over the Sea of Japan. The strong wind over the sea and the weak wind over the land are well recognized. These are due to the difference of the prescribed surface condition in the model. The small pressure trough to the south of Kanto District and southerly wind along the coastal region of the Sea of Japan to the west of Hokuriku District is not simulated. A finer horizontal resolution and improved treatment of the topographic effect will be necessary to simulate accurately these small scale features. The wind field shows discontinuous change near the peripheries of the forecast domain. This results from the lateral boundary condition. Although the inner field does not seem to be much contaminated by the noise, improving the lateral boundary condition is needed.

Fig. 13 shows various surface quantities predicted for the Case 1 along the line shown with circles in Fig. 2. The terms $\mathrm{H}$ and LW signify amounts of the sensible and latent heat supplies, respectively, $u_{*}$ the friction velocity, $|V|$ the wind speed at the lowermost level, $\Delta T$ the difference between the temperature at the lowermost level and at the sea surface. All the quantities are the mean values over 6 hours from $t=7$ to $t=12$. The numerals along the abscissa indicate the grid number counted from the upper left to the lower right corner of the forecast domain. The grid points 7,8 and 20 through 23 represent the land

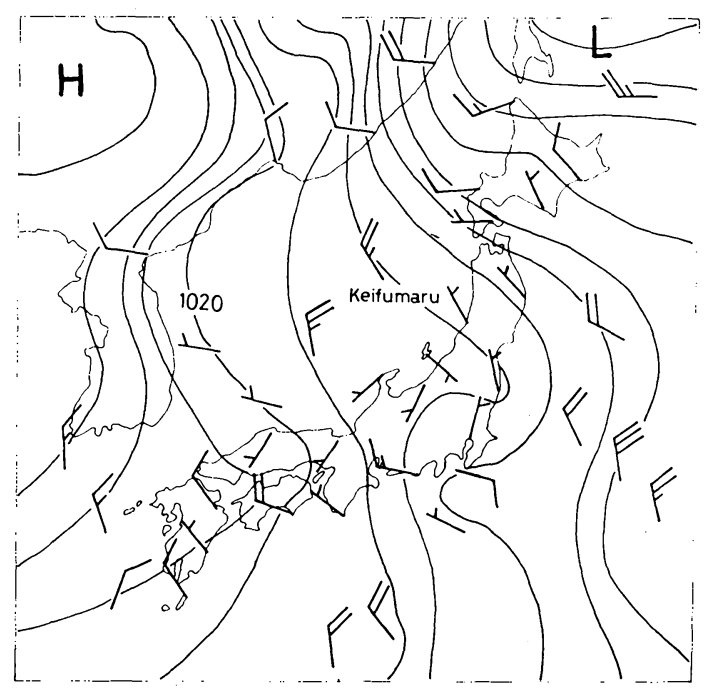

Fig. 12 Surface synoptic chart at 12 GMT 31 January 1977. Isobars are drawn at every $2 \mathrm{mb}$. 
surface and remaining grid points the sea surface. The air-sea temperature difference in the present experiment does not vary much across the Sea of Japan. Therefore the low level wind speed mostly determines the distribution of the amount of the energy supply and that of momentum exchange at the surface. Bowens ratio is 1.7 near the coast of the continent and 1.0 near the coast of the Japanese Islands.

Fig. 14 represents the vertical distribution of the effect of the sub-grid scale processes for the Case 1 along the same line with Fig. 13. The solid line indicates the warming rate (a) and moistening rate (b) averaged over 6 hours from $t=7$ to $t=12$. The thick dotted line and the shaded area indicate the uppermost level which is affected by the convective adjustment and the region where large scale condensation is calculated, respectively, during the last 6 hours of prediction period. Over the sea immediately off the land surface on the lee side, transformation of the atmospheric property is very large. This is because a large amount of sensible heat and moisture supplied from the sea surface are distributed vertically within the thin layer.

Asai and Nakamura (1978) in their numerical experiment showed that space mean relative humidity at the cumulus cloud base is about $85 \%$. Ninomiya (1964) statistically estimated that the relative humidity in the cloud layer of dense cumulus or stratocumulus is more than

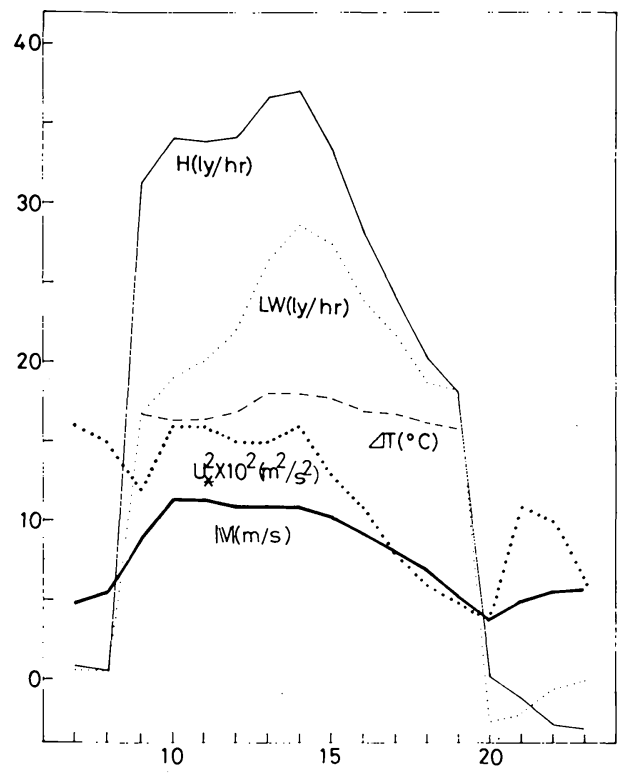

Fig. 13 Predicted surface quantities along the line shown with circles in Fig. 2.
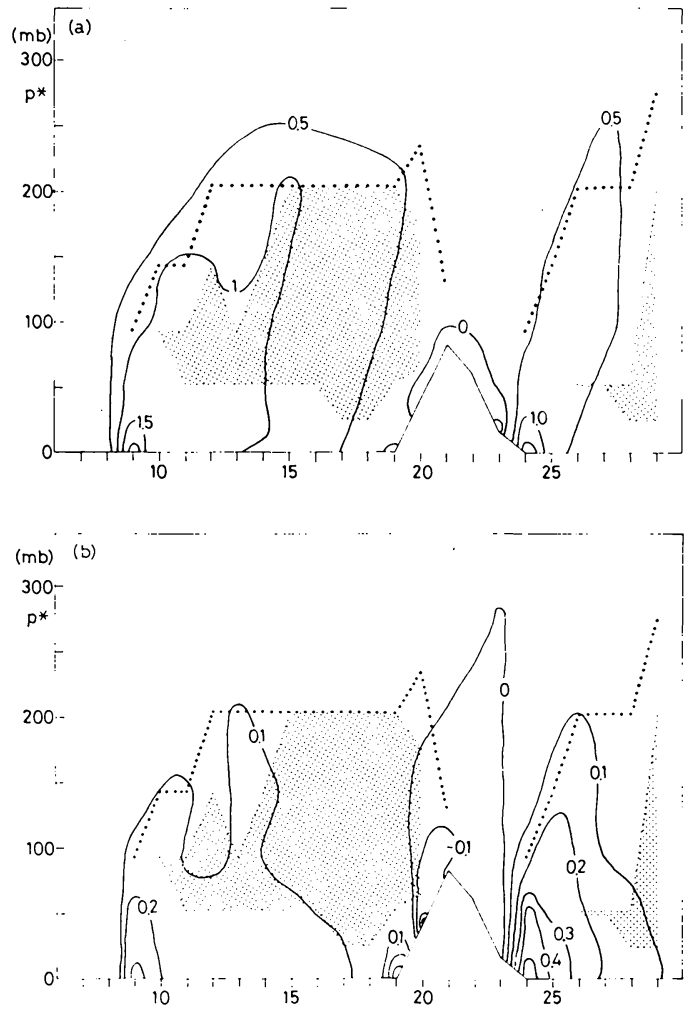

Fig. 14 The vertical distribution along the line shown with circles in Fig. 2 of warming rate (a) $\left({ }^{\circ} \mathrm{K} / \mathrm{hr}\right)$ and moistening rate (b) $(\mathrm{gr} / \mathrm{kg} / \mathrm{hr})$ due to the vertical sub-grid scale processes.

$85 \%$ over the Sea of Japan during winter season. The mean relative humidity shown in Fig. 4 exceeds $85 \%$ at the level $100 \mathrm{mb}$ above the surface. We regard this level as the height of the observed cloud base. The predicted relative humidity in the $\mathrm{M}$ model is more than $85 \%$ from the lowermost level upward until around the base of the stable layer. However we may consider that the shaded region of Fig. 14 is the cloud layer predicted by the present model. The base of the predicted cloud base $\left(p^{*} \sim 50 \mathrm{mb}\right)$ is lower than the observed one by 50 mbs.

The convective adjustment is predicted to reach almost the same height, i.e., $200 \mathrm{mb}$ above the surface, from the central part of the Sea of Japan to the coast of Japanese Islands. This seems to be a great discrepancy from that observed. Yamagishi (1980) compared vertical soundings over the Sea of Japan with those at coastal region under the typical northwest monsoon situation. He suggests that the top of the active convection is 50 

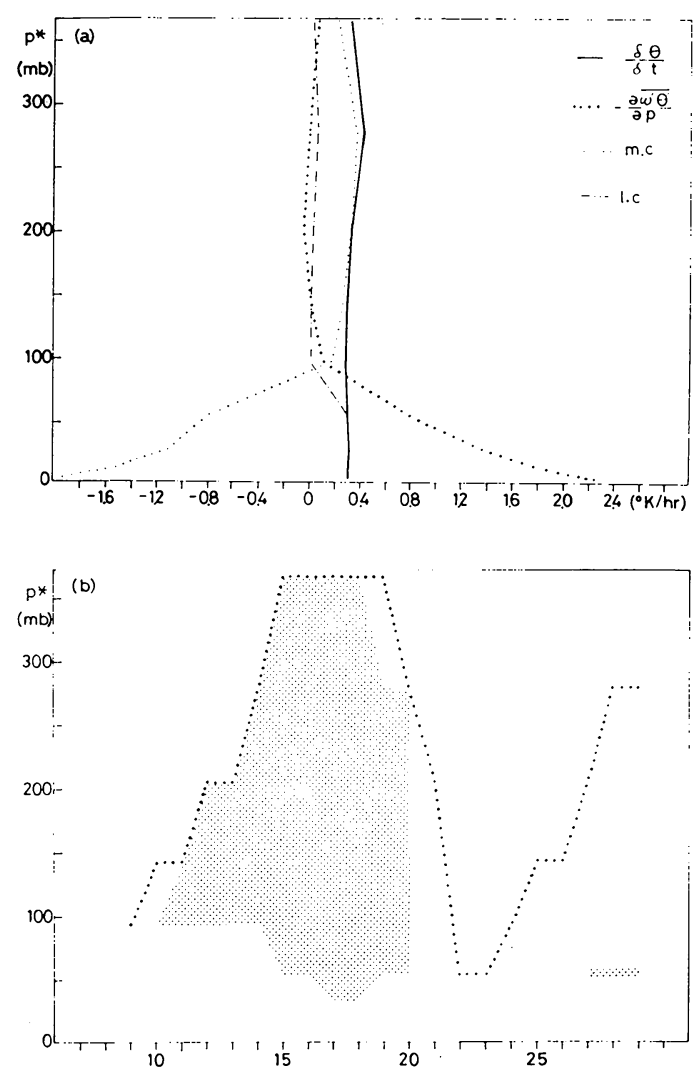

Fig. 15 Explanations are the same with Fig. 7(a) but for the Case 3(a). Explanations are the same with Fig. 14(a) but for the Case 3(b).

to $100 \mathrm{mb}$ higher over the coastal region of the Sea of Japan than over the eastern part of the Sea of Japan.

Next we will show results for the Case 3 in which the cold vortex at $500 \mathrm{mb}$ is observed over the Sea of Japan. Fig. 15(a) shows the warming and cooling rate for the Case 3 due to the subgrid scale processes at the grid point near the cross in Fig. 2. The grid point is under the predicted cold vortex center at the $500 \mathrm{mb}$ level. The height of the orography of Japanese Islands is set to be $1 \mathrm{~m}$ everywhere for the Case 3. Fig. 15(b) shows the vertical extent of the moist convective adjustment and the region where the large scale condensation is calculated during the last 6 hours of prediction period. The convective adjustment reaches to about $360 \mathrm{mb}$ above the surface. The vertical transport of heat upward from about $100 \mathrm{mb}$ above the surface is mostly brought about by the convective adjustment. The humid region reaches about $360 \mathrm{mb}$ above the surface near the cold vortex center. Ninomiya (1968) evaluated heat and water budget over the Sea of Japan during winter seasons. He showed that convective motions transported heat and moisture up to $600 \mathrm{mb}$ under the situation of strong cold air outbreak. Although we have no observation over the Sea of Japan for the Case 3, predicted height of the moist convection will be reasonable considering the above mentioned study.

(4) Amount of energy supply from sea surface and condensation amount

Manabe (1957, 1958) and Ninomiya (1968) evaluated the amount of heat energy supply from the Sea of Japan on the basis of the atmospheric budget analysis. They pointed out that the Bowens ratio obtained through budget analysis is much larger than that estimated by the bulk method. We compare the amount of the heat energy supply calculated in the present experiment with those mentioned above. Table 1 summarizes the results. In the Table values within parenthesis denote those estimated by bulk method. In our case the tabulated amount is twice the amount accumulated from $t=0$ to $t=$ 12. The present experiments calculate larger amount of latent heat supply than the budget analyses of the above mentioned authors. The magnitude of Bowens ratio of the present experiment is smaller than those by the budget analyses but slightly larger than those previously estimated by the bulk method. The above conclusion applies also to the results of the $\mathrm{L}$ model. The $\mathrm{L}$ model calculates slightly less amount of latent heat supply than the $\mathbf{M}$ model. Therefore the Bowens ratios predicted by the $\mathrm{L}$ model are 0.1 less than those shown in Table 1 for both the Cases 1 and 2.

Keifumaru observes sea surface temperature and wind, temperature and humidity at the deck level. We show in Fig. 16 the amount of heat energy supply and the Bowens ratio calculated from these data by using the approximate formula of Kondo (1975). Wind and temperature are observed at $18 \mathrm{~m}$ and $13 \mathrm{~m}$ above sea level, respectively. However the above calculation assumes that both the data are those at $10 \mathrm{~m}$ above the surface. Bowens ratio is small when surface air temperature is high and becomes large when surface air temperature is low. Bowens ratio ranges from 0.7 to 1.5 from 00 GMT 30 January to 00 GMT 8 February 1977. Average value during this period is 1.1 . The 12-hour mean energy supply and Bowens ratio of the present experi- 
Table 1. Energy supply from the Sea of Japan and the Bowens ratio.

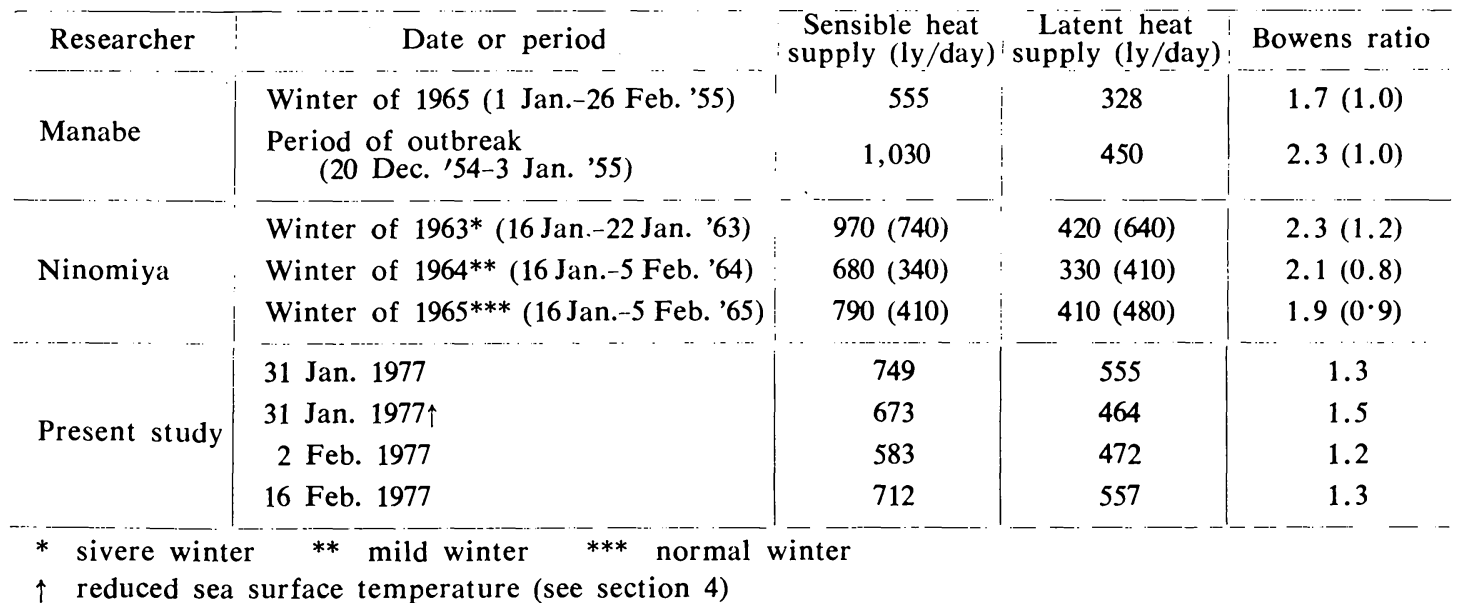

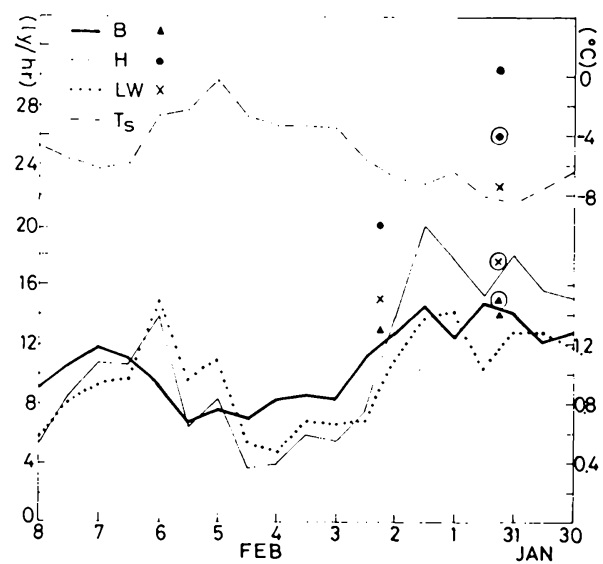

Fig. 16 Temporal variation of sensible heat supply $(\mathrm{H})$, latent heat supply (LW), Bowens ratio (B) and surface air temperature $\left(T_{s}\right)$. The values predicted by the present experiment are denoted by $(\mathrm{H}), \times(\mathrm{LW})$ and $\Delta(\mathrm{B})$, respectively. Circle signifies that the value within it refers to that for reduced sea surface temperature (see section 4).

ment at the grid point near the ship are also shown. The Bowens ratios of the present experiment are almost the same as those estimated by Kondo's bulk formula. However the amount of energy supply of the former is much larger than those of the latter. The difference between the two mainly results from the following two reasons; (1) the sea surface temperature observed by Keifumaru is about $5{ }^{\circ} \mathrm{C}$ (in the Case 1) and $2^{\circ} \mathrm{C}$ (in the Case 2) lower than those used in the present experiment, (2) the exchange coefficients
Table 2. Ratio of the condensation amount $\left(Q_{\text {con }}\right)$ to that evaporated from the Sea of Japan $\left(Q_{\text {evp }}\right)$.

\begin{tabular}{|c|c|c|c|}
\hline & $\begin{array}{c}\text { Case 1 } \\
\text { 00 GMT } 31 \\
\text { JAN. 1977 }\end{array}$ & $\begin{array}{r}\text { Case } 2 \\
\text { 00 GMT } 2 \\
\text { FEB. } 1977\end{array}$ & \begin{tabular}{|c} 
Case 3 \\
00GMT 16 \\
FEB 1977
\end{tabular} \\
\hline $\begin{array}{l}Q_{\text {con }} \\
Q_{\text {evp }}\end{array}$ & 0.24 & 0.16 & 0.33 \\
\hline
\end{tabular}

of Kondo's formula are smaller than the effective exchange coefficients used in the present experiments. At 12 GMT 31 January observed wind speed $\left(V_{s}\right)$ and air-sea temperature difference $\left(\Delta T_{s}\right)$ are $11 \mathrm{~m} / \mathrm{s}$ and $9.6^{\circ} \mathrm{C}$, respectively. Exchange coefficients of Kondo for sensible heat $\left(C_{h}\right)$ and latent heat $\left(C_{e}\right)$ are $C_{h} \sim C_{e} \sim 1.5 \times 10^{-3}$. The exchange coefficients of our experiment around above values of $V_{s}$ and $\Delta T_{s}$ are $C_{h}=$ $C_{e} \sim 2.0 \times 10^{-3}$. For the detailed discussion of the magnitude of exchange coefficients of bulk aerodynamic method see Yamagishi (1976).

Fig. 17(a), (b) show the 12-hour accumulation of the predicted condensation amount for the Case 1 and for the Case 3, respectively. Fig. 18(a), (b) show the 24-hour accumulation of the observed snowfall amount corresponding to Fig. 17(a), (b), respectively. Predicted precipitation amount is large around areas where a large amount of snowfall is observed. However predicted precipitation amount is about one fifth of the observed one along the coastal region of the Sea of Japan. Ninomiya (1964) made budget analysis of moisture and water vapor under the heavy snowfall situation and showed that the condensed water substance transported from the Sea of Japan accounted for a large part of precipitation along the coastal region of the Sea 

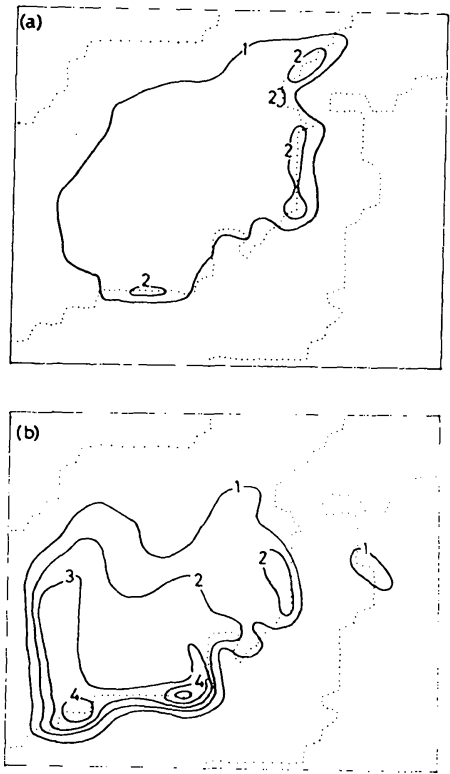

Fig. 17 12-hour accumulation of the predicted condensation amount (unit $\mathrm{mm} / 12 \mathrm{hr}$ ) for the Case 1(a) and for the Case 3(b), respectively. Periphery of the land is denoted by dotted line.
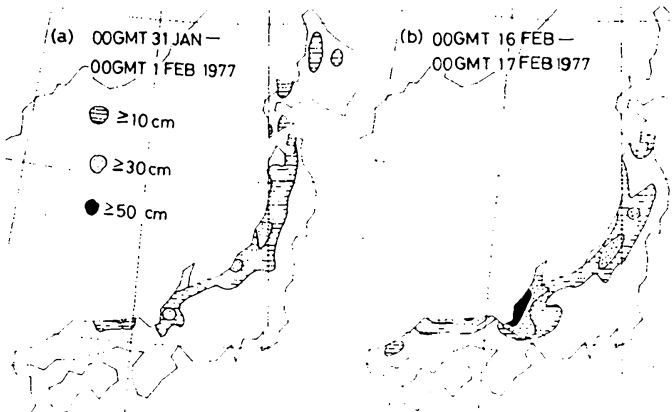

Fig. 18 Observed snowfall amount during 24hours.

of Japan under the northwest monsoon situation. Therefore we must integrate an equation for the condensed substance to improve the precipitation prediction along the coastal region.

According to Ninomiya (ibid), about $60 \%$ of the moisture evaporated from the Sea of Japan is condensed there. About $70 \%$ of the condensed substance is precipitated out there and the remaining is carried away to the coastal region of the Sea of Japan. Table 2 shows the ratio of the amount of condensation over the Sea of Japan to that of water vapor evaporated from the Sea of Japan for the present experiment. The values calculated in the present experiment are one third to one half of that obtained by Ninomiya (ibid).

\section{A sensitivity test}

We discuss here the results of a sensitivity test. The purpose is to see the effect of sea surface temperature variation upon the prediction. There are analyses which indicate that the local anomaly of the sea surface temperature greatly affects the convective activity in winter. Matsumoto and Ninomiya (1966) showed that the cloud amount distribution over the Sea of Japan under the weak monsoon is very sensitive to the meso-scale variation of the sea surface temperature. Saito (1975) studied the characteristics of inversion layers around the AMTEX area. He states that the base of the inversion layer tends to rise as the air current crosses over the Kuroshio current. The fact suggests that the heating from the sea contributes to increase the height of the inversion base. The horizontal resolution of the present model is not fine enough to resolve these mesoscale features. However it is helpful for future improvement to investigate the extent to which the present model reacts to anomaly of the sea surface temperature. We compare two results which use different sea surface temperature distribution. Fig. 19 shows the sea surface temperature. The thick line is the one used for the experiment hitherto described for the Case 1. The dotted line indicates the anomaly of the sea surface temperature, which is used for the sensi-

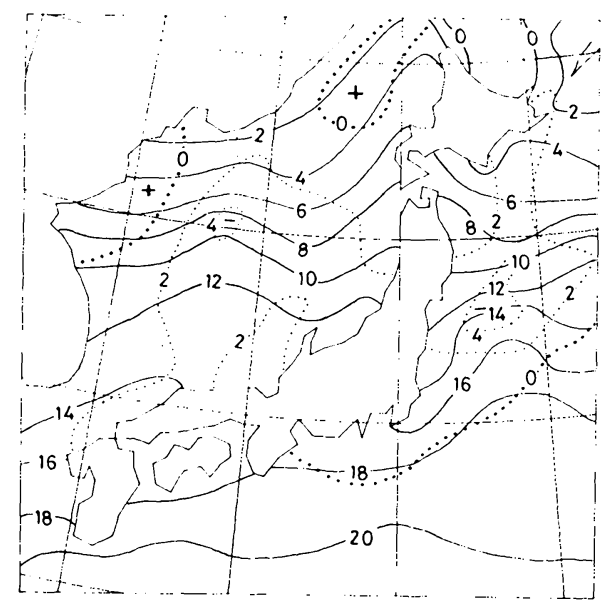

Fig. 19 The sea surface temperature used for the present experiment (solid line, ${ }^{\circ} \mathrm{C}$ ) and the anomaly of the sea surface temperature used for the sensitivity test. 
tivity test (the negative sign indicates the decrease of the sea surface temperature for the sensitivity test). The anomaly is obtained from the sea surface temperature of a different year. Some results of this test are already discussed in section
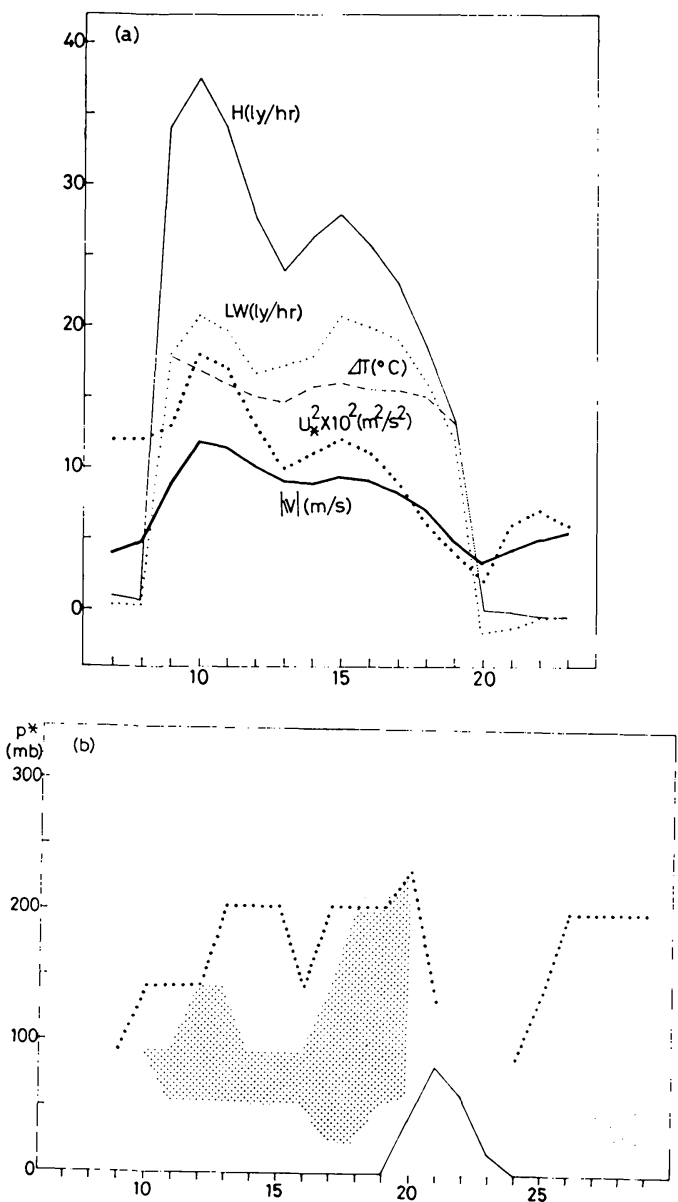

Fig. 20 The same with Fig. 13 except for the different sea surface temperature (a). The same with Fig. 14(a) except for the different sea surface temperature (b).
3(2) and 3(4). Fig. 20(a), (b) show the results corresponding to Fig. 13 and Fig. 14(a), respectively. The reduced surface temperature decreases energy supply from the sea surface. Decrease of energy supply changes temperature field, pressure field and wind speed. The change of the wind speed at the lowest level roughly follows that of the pressure field (Table 3). Decreasing the sea surface temperature by $3 \sim 4^{\circ} \mathrm{C}$ decreases potential temperature and the wind speed at the lowest level by about $1^{\circ} \mathrm{K}, 1 \sim 2 \mathrm{~m} / \mathrm{s}$, respectively, around the central part of the Sea of Japan (Table 3). The decrease of energy supply, wind speed and the decrease of the vertical extent of the humid area and the convective adjustment are largest around the area where the negative anomaly of the sea surface temperature becomes largest. Although the above discussion is qualitative, it suggests that the accurate sea surface temperature should be used for the meso-scale model under these situation.

\section{Other remaining problems}

In addition to problems mentioned above, the following points are worth while to be studied.

(a) The initialization of PBL. The present initialization process does not consider the boundary layer effect. Consequently the wind speed at the lowest level undergoes unreasonably rapid change, particularly over the land, immediately after the start of time integration. Therefore large amplitude gravitational modes are likely to be excited. Tapp and White (1976) solves Ekman layer equation to obtain the wind from the pressure field. We intend to apply this method to adjust the lower tropospheric wind. Eventually the dynamic initialization such as proposed by Kurihara and Tuleya (1977) may be more desirable.

(b) The initialization procedure to adapt the air flow to the existence of mountain. At present, the balance equation and the quasi-geostrophic

Table 3. Difference of the sea surface temperature $\left(\Delta T_{s}\right)$ and the change of the predicted potential temperature $(\Delta \theta)$, geostrophic wind speed $\left(\Delta V_{g}\right)$ and of the wind speed $(\Delta V)$ at the lowest level averaged over 6 hours from $t=7$ to $t=17$. Negative sign indicates the decrease of the quantity for the sensitivity test. Numbering of the grid is the same with that of Fig. 20(a).

\begin{tabular}{c|r|r|r|r|r|r|r|r|r|r|r}
\hline No. of grid point & \multicolumn{1}{c}{9} & \multicolumn{1}{c}{10} & \multicolumn{1}{c}{11} & 12 & 13 & 14 & 15 & 16 & 17 & 18 & 19 \\
\hline$\Delta T_{s}\left({ }^{\circ} \mathrm{C}\right)$ & 0.5 & 0.3 & -0.4 & -2.0 & -4.0 & -3.2 & -2.6 & -2.2 & -1.9 & -1.7 & -3.3 \\
$\Delta \theta\left({ }^{\circ} \mathrm{K}\right)$ & -0.3 & -0.1 & -0.3 & -0.8 & -1.1 & -1.0 & -0.9 & -0.8 & -0.7 & -0.8 & -1.0 \\
$\Delta V_{g}(\mathrm{~m} / \mathrm{s})$ & 0.8 & 1.1 & -0.3 & -1.7 & -2.0 & -0.9 & -0.2 & 0.1 & 0.4 & 0.1 & -0.1 \\
$\Delta V(\mathrm{~m} / \mathrm{s})$ & 0.1 & 0.4 & 0.2 & -0.7 & -1.8 & -1.8 & -0.8 & 0.0 & 0.3 & 0.1 & -0.4 \\
\hline
\end{tabular}


$\omega$-equation are solved on the isobaric surface without considering the presence of the topography. The wind field obtained on the $p$-surface is then interpolated to yield that on the $\sigma$-surface. This procedure also seems to experience a large initial shock. The initialization method including the orography such as that proposed by Kondo and Nitta (1979) will be needed to accomplish the adjustment of the initial wind field around the mountain.

(c) Our main concern to date is to see the extent to which air-mass transformation over sea during winter season could be simulated. Therefore no specific analysis is presented concerning the air flow over the land. Although the present model predicts the diurnal variation of energy supply and momentum exchange over the land, these features need further extensive analysis and assessment.

\section{Summary}

A three dimensional model with the detailed PBL parameterization is applied to the observed meteorological field under the northwest winter monsoon situation. The items discussed in this paper are; (1) The heat, moisture and momentum budgets due to the sub-grid scale processes. (2) The amount of energy supply from the Sea of Japan and the amount of condensation. (3) The sensitivity of the model to the variation of the sea surface temperature. The main results of the study are summarized as follows:

(1) The present model simulates the general features of the mixed layer. However further investigation is required to improve the parameterization of moist convection and the condensation process. In particular the moist convective adjustment scheme of the present model brings about unreasonably large cooling and too humid stratification near the surface.

(2) The vertical profile of potential temperature and wind speed in the lower troposphere are fairly well simulated. However the predicted relative humidity is rather larger than the observed one.

(3) The base of the predicted stable layer is higher than the observed one by about $60 \mathrm{mb}$. Not only the PBL and the convection parameterization but also accurately predicting the large scale adiabatic motion in the free atmosphere is important for accurately simulating the height of the stable layer.

(4) The latent heat released by condensation warms the layer below the stable layer. Increasing temperature in the mixed layer shifts the base of the stable layer upwards.

(5) The momentum change due to the vertical turbulent transfer nearly compensates that due to the ageostrophic wind components below 100 $120 \mathrm{mb}$ above the surface. The deviation of the wind direction from the geostrophic wind change the sign at about $100 \mathrm{mb}$ above the surface.

(6) Features of momentum budget and magnitude of momentum change by turbulent transfer are similar to those analytically obtained around the AMTEX area.

(7) Amounts of latent heat supply from the Sea of Japan calculated in the present experiment are larger than those obtained by the budget analyses. Consequently the Bowens ratios in the present experiment $(\sim 1.3)$ are rather smaller than those obtained by the budget analyses $(\sim 2.0)$. However they are larger than those estimated by the bulk method $(\sim 1.0)$.

(8) Space distribution of the predicted precipitation qualitatively agrees with that of the observed snowfall along the coastal region of the Sea of Japan. However the predicted precipitation amount is about one fifth of the observed one.

(9) The ratios of the amount of water vapor condensed over the Sea of Japan to that evaporated from the Sea of Japan are 0.16 0.32. The values are one third to one half of those estimated by budget analysis under heavy snowfall situations.

(10) Sensitivity test shows that accurate sea surface temperature should be used for the simulation of air-mass transformation of winter season. Reducing sea surface temperature $3 \sim 4^{\circ} \mathrm{C}$ decreases potential temperature and wind speed at the lowest level about $1^{\circ} \mathrm{K}, 1 \sim 2 \mathrm{~m} / \mathrm{s}$, respectively.

\section{Acknowledgements}

The present author is thankful to Dr. H. Matano, former head of the Electronic Computation Center, JMA and to Mr. T. Yoshida, head of the ECC for their encouragement throughout this work. Sincere gratitude is due to Drs. Ta. Nitta and $\mathrm{K}$. Ninomiya for their encouragement and critical discussions throughout this work, which contribute to improve the original manuscript of the present paper. Thanks are also due to Dr. T. Kitade and to other staff members of the ECC for their fruitful discussions. 


\section{Appendix 1}

Table A.1 Quantities used for solving (15). The symbol $\zeta$ is the zenith angle, $e_{a}$ the vapor pressure and $Z_{s}$ the height of orography in unit of meter.

$$
\begin{aligned}
(\operatorname{tau}) & =a+b \times 10-0.13 \sec \zeta \\
b & =0.43+0.016 e_{a} \\
a & =1-b-0.06 \log _{10} e_{a} \\
\left(R_{s}\right)_{\infty} & =0.325(l y / \mathrm{sec}) \\
A & =0.6 \\
z_{0} & =0.2 \mathrm{~m} \\
\left(H_{g}\right)_{0} & =10^{-4}\left\{\left(T_{g}\right)_{0}-T G I\right\} \quad(l y / \mathrm{sec}) \\
T G I & =277-0.006 Z_{s} \quad\left({ }^{\circ} \mathrm{K}\right)
\end{aligned}
$$

\section{Appendix 2}

Choice of constant $B$ in (21)

The magnitude of $B$ used in the present experiment is

$$
B=3 \times B_{0}, \quad B_{0}=6.75 \times 10^{-3}
$$

The above value gives the similar result with the one obtained using (17) through (20) (hereafter called M.Y. formula) in the experiment using the one dimensional model (coarse model of Yamagishi, 1979). According to Blackadar (1962), the value of $B$ is about $6.75 \times 10^{-3}$ when the surface geostrophic wind, roughness parameter and the Coriolis parameter are taken to be $10 \mathrm{~m} \mathrm{~s}^{-1}$, $0.2 \mathrm{~m}$ and $10^{-4} \mathrm{~s}^{-1}$, respectively. This is close to the value $\left(6 \times 10^{-4}\right)$ recommended by $\mathrm{Wu}$ (1965). The magnitude of $B$ in the present experiment is almost three times as large as those mentioned above. Fig. A.1 compares the results obtained by M.Y. formula and by (21) in one dimensional model experiment. Initial conditions and computational procedures are the same with those of Yamagishi (1979).

\section{Appendix 3}

The assumption that terms $S_{m}, S_{h}$ do not tend to zero even in very stable region allows the downward heat flux across the stable layer.

Fig. A. 2 shows the effect of the downward heat flux on the thermal stratification. Dotted lines indicate results when the original formula is used and solid lines those of the present experiment. Both are results of the D model for the Case 1 . In this case our assumption gives about $1.5^{\circ} \mathrm{K}$ higher temperature below the stable layer than the original formula. The large downward heat

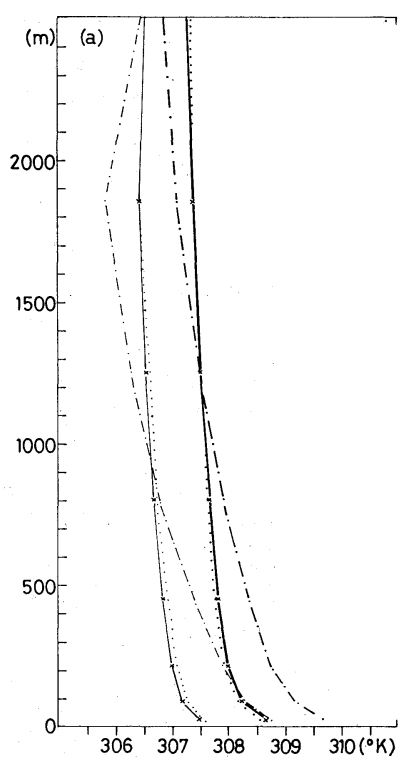

(a)

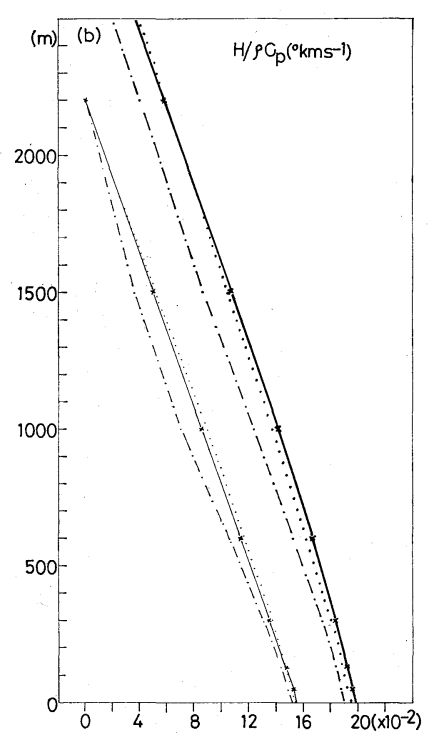

(b)

Fig. A.1 The vertical profile of potential temperature (a) and heat flux (b) at 1400 LST. The thick lines show the results when roughness parameter $\left(z_{0}\right)$ is 0.2 $\mathrm{m}$ and the thin lines those when $z_{0}$ is $0.00032 \mathrm{~m}$, respectively. The solid lines indicate the results of M.Y. formula, dotted lines those of (21) when $B=3 \times B_{0}$ and the dash-dotted lines those of (21) when $B=$ $B_{0}$, respectively. 


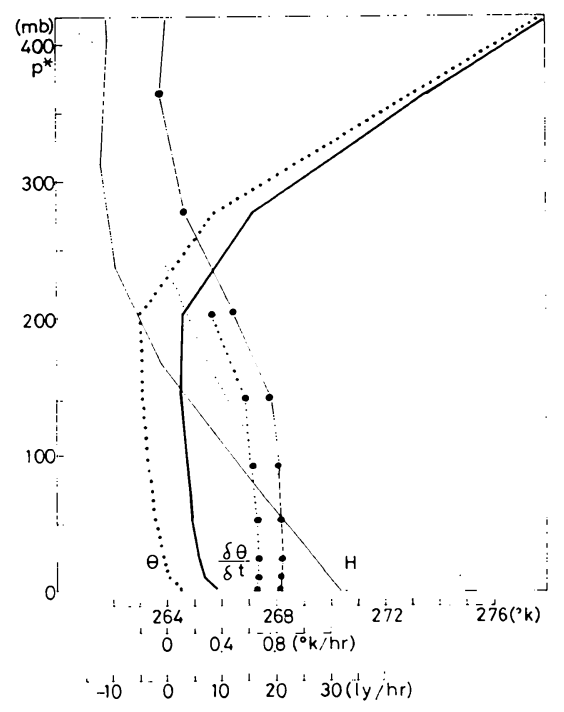

Fig. A2 Predicted potential temperature $(\theta)$ at $t=12$ and warming rate $(\delta \theta / \delta t)$, heat flux $(\mathrm{H})$ averaged over 6 hours from $t=7$ to $t=12$.

flux far above the stable layer is not reasonable. However this heat flux is found to have very small effect on the predicted temperature field above the stable layer.

\section{References}

Asai, T. and K. Nakamura, 1978: A numerical experiment of airmass transformation process over warm sea. Part 1: Development of a convectively mixed layer. J. Meteor. Soc. Japan, 56, 424-434.

Barker, E. H. and L. B. Thomas, 1975: A note on the computation of atmospheric surface layer fluxes for use in numerical modeling. J. Appl. Meteor., 14, 620-622.

Blackadar, A. K., 1957: Boundary layer wind maxima and their significance for the growth of nocturnal inversion. Bull. Amer. Meteor. Soc., $38,283-290$.

Businger, J. A., J. C. Wyngaard, Y. Izumi and E. F. Bradly, 1971: Flux-profile relationships in the atmospheric boundary layer. J. Atmos. Sci., 28, 181-189.

Chouinard, C., 1979: Simulation of east coast cyclogenesis using a primitive equation model coupled with a detailed planetary boundary layer formulation. Publication in Meteorology, No. 122, McGill Univ., $162 \mathrm{pp}$.

Clarke, R. H., 1970: Recommended method for the treatment of the boundary layer in numerical models. Australian Meteor. Mag., 18, 51-71.
Davies, H.C., 1976: A lateral boundary formulation for multi-level prediction models. Quart. J. Roy. Meteor. Soc., 102, 405-418.

Kondo, H. and Ta. Nitta, 1979: A case study of the initialization of the meteorological fields including topography. J. Meteor. Soc. Japan, 57, 300-307.

Kondo, J., 1975: Air-sea bulk transfer coefficients in diabatic conditions. Bound. Layer Meteor., 9, 91-112.

- 1976: Heat balance of the East China Sea during the air mass transformation experiment. J. Meteor. Soc. Japan, 54, 382-398.

Kurihara, Y. and R.E. Tuleya, 1977: A scheme of dynamic initialization of the boundary layer in a primitive equation model. Mon. Wea. Rev., 106, 114-123.

Leith, C. E., 1969: Two dimensional eddy visicosity coefficients. Proc. WMO/IUGG Symp. Num. Wea. Pred., Tokyo, November 26-December 4, 1968, Japan Meteorological Agency, 1-41.

Manabe, S., 1957: On the modification of air mass over Japan Sea when the outbreak of cold air predominates. J. Meteor. Soc. Japan, 35, 311326.

, 1958: On the estimation of energy exchange between the Japan Sea and the atmosphere during winter based upon the energy budget of both the atmosphere and the sea. J. Meteor. Soc. Japan, 36, 123-133.

Matsumoto, S. and K. Ninomiya, 1966: Some aspects of the cloud formation and its relation to the heat and moisture supply from the Japan Sea surface under a weak winter monsoon situation. J. Meteor. Soc. Japan, 44, 60-74.

and —-1967: On the mesoscale warm core above the condensation level related to convective activities under the influence of dome shaped cold air. J. Meteor. Soc. Japan, 45, 306-314.

Mellor, G. L. and T. Yamada, 1974: A hiearchy of turbulence closure models for planetary boundary layers. J. Atmos. Sci., 31, 1791-1806.

Miyakoda, K. and J. Sirutis, 1977: Comparative integrations of global models with various parameterized processes of subgrid-scale vertical transports: Description of the parameterizations. Beitr. Phys. Atmos., 50, 445-487.

Ninomiya, K., 1964: Water-substance budget over the Japan Sea and the Japan Islands during the period of heavy snow storm. J. Meteor. Soc. Japan, 42, 317-329.

1968: Heat and water budget over the Japan Sea and the Japan Islands in winter season-With special emphasis on the relation among the supply from sea surface, the convective transfer and the heavy snowfall. J. Meteor. Soc. Japan, 46, 343-372. 1976: Wind profile and kinetic energy 
budget in the mixed layer of polar air-mass transformed over Kuroshio region. J. Meteor. Soc. Japan, 54, 361-369.

and T. Akiyama, 1976: Structure and heat energy budget of mixed layer capped by inversion during the period of polar outbreak over Kuroshio region. J. Meteor. Soc. Japan, 54, 160174.

Nitta, Ta., Y. Yamagishi and Y. Okamura, 1979: Operational performance of a regional numerical weather prediction model. J. Meteor. Soc. Japan, 57, 308-331.

Paulson, C. A., 1970: The mathematical representation of wind speed and temperature profiles in the unstable atmospheric surface layer. J. Appl. Meteor., 9, 857-861.

Saito, N., 1975: A synoptic study of the inversion during the AMTEX'74. Pap. Met. Geophys., 26, 121-147.

Tapp, M. C. and P.W. White, 1976: A non-hydro- static mesoscale model. Quart. J. Roy. Meteor. Soc., 102, 277-296.

Wu, S. S., 1965: A study of heat transfer coefficients in the lowest 400 meters of the atmosphere. J. Geophys. Res., 70, 1801-1807.

Yamada, T. and G. L. Mellor, 1979: A numerical simulation of BOMEX data using a turbulence closure model coupled with ensemble cloud relations. Quart. J. Roy. Meteor. Soc., 105, 915944.

Yamagishi, Y., 1976: On coefficients for use in bulk aerodynamic method (in Japanese). Tenki, 23, 133-137.

1979: Level-2 version of the turbulence closure model applied to the model with coarse vertical resolution (in Japanese). Tenki, 26, 449457.

1980: Some characteristics of the stable layer over the Japan Sea during winter season (in Japanese). Tenki, 27, 322-329.

\title{
境界層のパラメタリゼーションを精密に扱った数値モデル による気団変質のシミュレーション
}

\author{
山 岸 米 二 郎
}

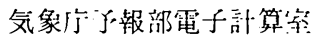

この論文は 3 次元モデルによる冬期の父润変斦過程の数值シミュレーションを論ずる。このモデルの特徵は大 父下層の鈆值分解能を密にし，境界層のパラメタリゼーションを橉密に扱ら努力をしていることである。モデル は以下の物理過程を扱っている。

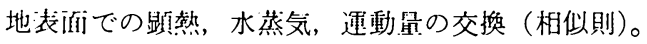

乱流による鉛ifi渦执散効果 (Mellor and Yamada (1974) のレベル2の closure model)。

刘流活動の集搏効果（潤潤対流調節）

水䕩文の㠜結（大規模凝絬）

水平の洲拓敬効果

このモデルを冬の山本海の北西季節風時の解析值に適用し，3つのケースについて12時閂䅡分を行った。

得られた結論の要約は以下の通りである。

(1) ここで採用されたバラメタリゼーションは混合層の全休的な特徵をかなりよくシミュレートしている。しか

し今後対流のバラメタリゼーションを改凅することが大切である。

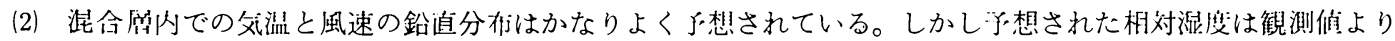
かなり大きい。

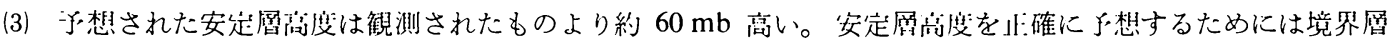
内の過程の及ならず，大規模な断熱運動（水平移流，鉛南移流）の正確な予想も大切である。

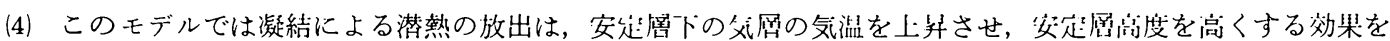
持つ。

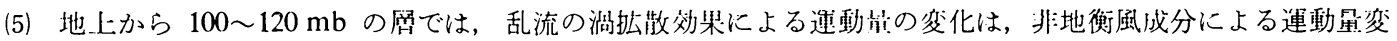

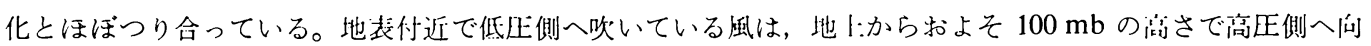
く成分を持ち，そのすぐ上から际び低正側へ问く成分を持つ。ここで得られた運動监の収支は AMTEX 領域 で解析的に得られた結果と類似している。 
(6) この尖験で得られた日本海での潜熱補給徰はこれまで収支解析で得られたものより多い。従ってここで得ら れたボーエン比は収文解析で得られた值より小さい。ここで得られたボーエン比（1.3）は近藤のバルク公式 で見积った值とほぼ一致する。しかしェネルギー補給星は近藤の公式で得られる㢟より大きい。

（7）子測された凝結冒の日本海沿岸部での分布は，観測された降非の分布と定性的に対応している。しかし一測 凝結员は観测された降水㨁のほぼ 1/5である。

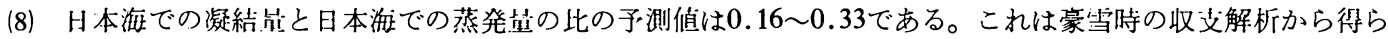
れた佔（０.6）の $0.33 〜 0.5$ である。

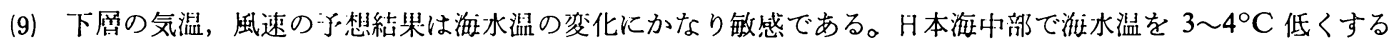
と最下層の父鼬と風速は冬々 $1^{\circ} \mathrm{C}, 1 \sim 2 \mathrm{~m} / \mathrm{s}$ 減少する。 